\title{
The dark art of light measurement: accurate radiometry for low-level light therapy
}

\author{
Mohammed A. Hadis ${ }^{1}$ (D) Siti A. Zainal ${ }^{2}$ - Michelle J. Holder ${ }^{2}$. James D. Carroll ${ }^{3}$ • \\ Paul R. Cooper ${ }^{2}$ Michael R. Milward ${ }^{2}$ - William M. Palin ${ }^{1}$
}

Received: 1 September 2015 / Accepted: 16 February 2016/Published online: 10 March 2016

(C) The Author(s) 2016. This article is published with open access at Springerlink.com

\begin{abstract}
Lasers and light-emitting diodes are used for a range of biomedical applications with many studies reporting their beneficial effects. However, three main concerns exist regarding much of the low-level light therapy (LLLT) or photobiomodulation literature; (1) incomplete, inaccurate and unverified irradiation parameters, (2) miscalculation of 'dose,' and (3) the misuse of appropriate light property terminology. The aim of this systematic review was to assess where, and to what extent, these inadequacies exist and to provide an overview of 'best practice' in light measurement methods and importance of correct light measurement. A review of recent relevant literature was performed in PubMed using the terms LLLT and photobiomodulation (March 2014March 2015) to investigate the contemporary information available in LLLT and photobiomodulation literature in terms of reporting light properties and irradiation parameters. A total of 74 articles formed the basis of this systematic review. Although most articles reported beneficial effects following LLLT, the majority contained no information in terms of how light was measured (73\%) and relied on manufacturerstated values. For all papers reviewed, missing information for specific light parameters included wavelength (3\%), light source type ( $8 \%$ ), power (41\%), pulse frequency (52\%),
\end{abstract}

Mohammed A. Hadis

HadisM@bham.ac.uk

1 Biomaterials Unit, School of Dentistry, College of Medical and Dental Sciences, University of Birmingham, St Chads Queensway, Birmingham, UK B4 6NN

2 Oral Biology, School of Dentistry, College of Medical and Dental Sciences, University of Birmingham, St Chads Queensway, Birmingham, UK B4 6NN

3 THOR Photomedicine Ltd, Chesham, UK beam area (40\%), irradiance (43\%), exposure time (16\%), radiant energy (74\%) and fluence (16\%). Frequent use of incorrect terminology was also observed within the reviewed literature. A poor understanding of photophysics is evident as a significant number of papers neglected to report or misreported important radiometric data. These errors affect repeatability and reliability of studies shared between scientists, manufacturers and clinicians and could degrade efficacy of patient treatments. Researchers need a physicist or appropriately skilled engineer on the team, and manuscript reviewers should reject papers that do not report beam measurement methods and all ten key parameters: wavelength, power, irradiation time, beam area (at the skin or culture surface; this is not necessarily the same size as the aperture), radiant energy, radiant exposure, pulse parameters, number of treatments, interval between treatments and anatomical location. Inclusion of these parameters will improve the information available to compare and contrast study outcomes and improve repeatability, reliability of studies.

Keywords Radiometry · Low-level light therapy $\cdot$ Low-level laser therapy $\cdot$ LLLT $\cdot$ Photobiomodulation

\section{Introduction}

'Low-level light therapy' (LLLT) or the recently accepted Medical Subject Heading (MeSH) term, photobiomodulation is the application of light typically within the wavelength range $\sim 600-1000 \mathrm{~nm}$ to directly stimulate or inhibit cellular and biological processes. The application of low power ( $<500 \mathrm{~mW}$; non-thermal and non-destructive) lasers or lightemitting diodes (LEDs; or even a combination of both) have shown therapeutic effects with a number of light parameters 
that include irradiance, exposure time and total energy delivered.

Many studies have reported beneficial effects of LLLT following trauma in improving tissue healing [1], reducing inflammation [2], reducing oedema [3], restoring blood flow [4] and inducing analgesia [5] in a number of medical specialties that include musculoskeletal injuries, skin diseases, degenerative diseases, neuropathic pain syndromes and even traumatic brain injuries [1-8]. Favourable data for LLLT in other biomedical areas now also exists, which includes several dental specialties such as endodontics, maxillofacial surgery, oral pathology, oral surgery, orthodontics, pediatric, periodontics and prosthodontics [9] for a range of conditions including oral mucositis [10], dentine hypersensitivity [11] and candidiasis [12]. The application of LLLT may also prevent pain and protect muscles prior to strenuous exercise or trauma, which has significant implications for the wider use of this therapeutic technology as a pre-conditioning modality prior to surgical procedures [13].

Despite several thousand in vitro studies, in vivo studies and clinical trials reporting positive beneficial effects, articles exist where nil or negative effects have been reported, promoting controversy surrounding the effectiveness of LLLT [14-18]. In certain studies, non-significant effects can be attributed to several factors relating to dosimetry; too much or too little energy, irradiance and exposure time as well as pulse structure and insufficient irradiation area [14, 19, 20]. It is clear that there is a therapeutic window in terms of dosimetry and a biphasic dose response which has been likened to the Arndt-Schulz or hormesis curve [19]. Consequently, irradiation parameters are likely to be key to whether outcomes have a positive, nil or negative effect. Although LLLT parameters are known and have been previously defined in the literature, including specialised mandatory and volunteer laser safety international standards such as US Code of Federal Regulations, American National Standards Institute and the International Standards Manual and other laser safety books and review articles [21, 22], beam parameters are often not measured, calibration of measuring instruments are rarely verified, critical data is often unreported, and in some cases, there are elementary dose calculation errors, all of which leading to misinformation in the literature. The importance of correct measurement and reporting has been emphasised several times within the literature [23-28] and brief 'guidelines' on how to measure and report LLLT dose and beam parameters in clinical and laboratory studies has also been published [23, 29, 30].

The aims of this work are to (1) review the adequacy of reporting irradiation parameters in recent literature, (2) describe fundamental concepts and appropriate methodology for best practice in light property evaluation and (3) define the correct terminology for reporting radiometric parameters.

\section{Methods}

To assess the methods and variability of measuring and reporting LLLT irradiation parameters, and radiometric terminology used by researchers, a review of recent relevant literature was performed in PubMed. The following two searches where performed separately: (low and level and light and therapy) and (photobiomodulation). These specific search terms were used as 'LLLT' has been widely recognised and used as a MeSH term for many years, although more recently photobiomodulation has become accepted as a more appropriate description of the action of light on cellular behaviour. Following the literature searches, the results were filtered for 'full-text article', published in a 1-year period between 19th March 2014 and 19th March 2015 (Fig. 1) to ensure a manageable number of articles whilst assessing the latest methods used by researchers. Review articles, editorials, articles in languages other than English and those not relevant to LLLT or photobiomodulation, were excluded and duplicates removed. The selected articles were assessed in terms of the method employed to measure light properties, reporting of light properties (source, wavelength, power, pulse frequency and beam area) and reporting of irradiation parameters (irradiance, exposure time, radiant energy and radiant exposure).

\section{Results}

The initial search of the PubMed database resulted in 2295 and 177 articles according to the search terms employed (LLLT and photobiomodulation, respectively), which were filtered and screened (Fig. 1a, b) to 56 [31-86] and 18 [87-104] articles, respectively. Thus, a total of 74 articles formed the basis of this systematic review (Tables 1 and 2).

The majority $(71 / 74 ; 96 \%)$ of articles reported a positive effect following LLLT, with three articles [43, 70, 87] reporting nil effects following LLLT (Table 2) and none reporting negative effects. Of the 74 articles, $73 \%(54 / 74)$ did not report methods for light measurement and relied on manufacturers' information. Only $5 \%(4 / 74)$ of articles reported a full set of data for the parameters/information assessed in this review [83-86]. For articles that did report light measurement methods, the most common was using a power meter $(22 \% ; 16 / 74)$, or equivalent. Remarkably, only six $(6 / 74 ; 8 \%)$ employed a method that was able to measure spectral properties such as wavelength $[39,45,54,67,68,83]$. Two articles $(3 \% ; 2 / 74)$ failed to report even manufacturers quoted wavelength $[48,61]$. Other parameters which were not reported were power $(41 \% ; 30 / 74)$, beam area $(41 \% ; 30 / 74)$, irradiance $(43 \% ; 32 / 74)$, exposure time $(16 \%, 12 / 74)$, radiant energy $(74 \% ; 55 / 74)$ and radiant exposure (fluence; $16 \% ; 12 /$ 74), and these are detailed in Tables 1 and 2. 
(a)

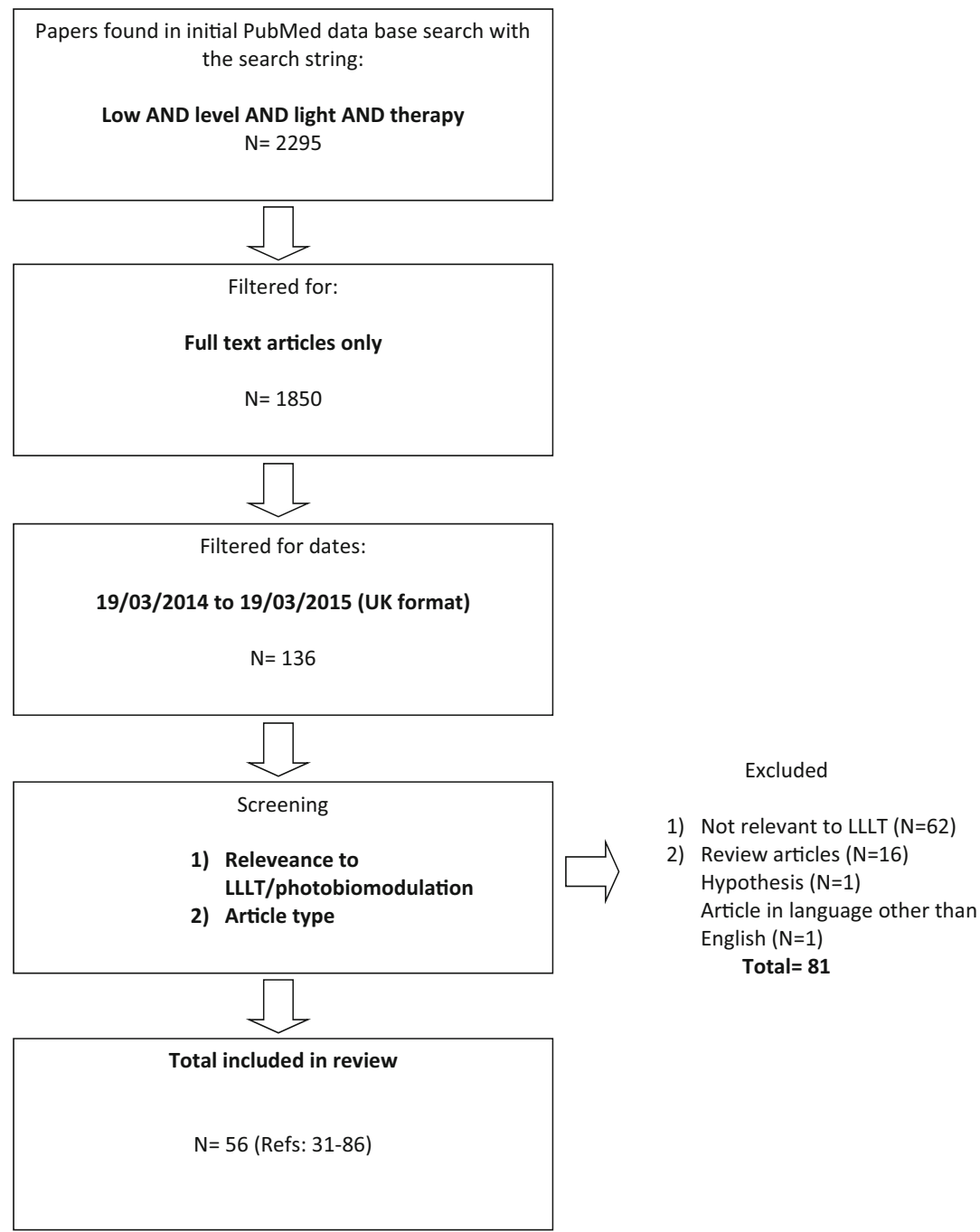

Fig. 1 a Flow chart of search strategy to identify articles for review using 'low and level and light and therapy.' b Flow chart of search strategy to identify articles for review using 'photobiomodulation'

\section{Discussion}

The need for the measurement and standardisation of reported irradiation parameters has previously been emphasised [22, 29, 30], and it was proposed that eight key beam parameters should be reported in all LLLT studies [29]: wavelength, power, irradiation time, beam area (at the skin or culture surface), pulse parameters (frequency), anatomical location (skin colour, target location, i.e. depth below skin), number of treatments and the interval between treatments. Whilst other radiometric parameters such as divergence, depth of field, beam polarisation, coherence length, beam profile and spectral width are also important, the authors of that paper suggested those parameters were the minimum necessary for a repeatable scientific study [29]. Thus, in agreement with that paper, a 'bare' minimum approach should be adopted when describing beam parameters and a more thorough approach should utilise more technically demanding techniques such as beam profiling. The importance of describing light parameters and treatment protocol has also been emphasised in several other publications [22-28]. Thus, the focus of this current study was to provide an overview of the fundamental concepts of light measurement and set the basis for a proper evaluation of light properties. Therefore, this study has reviewed the properties directly related to light rather than treatment protocol (anatomical location, number of treatments, interval between treatments).

In the current literature search, $96 \%$ of articles reported positive effects of LLLT with only three articles [43, 70, 87] showing no beneficial effect following LLLT. However, the number of articles that report measured information regarding light properties and irradiation 
(b)

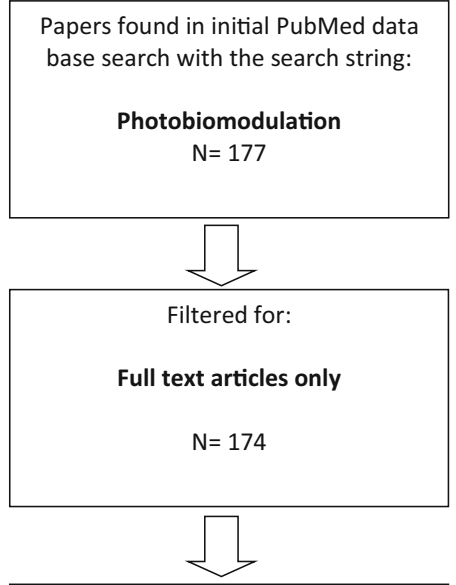

Filtered for dates:

19/03/2014 to $19 / 03 / 2015$ (UK format)

$\mathrm{N}=41$

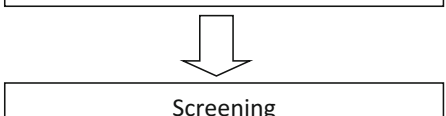

1) Relevance to LLLT/photobiomodulation

2) Article type

3) Duplicates from LLLT search

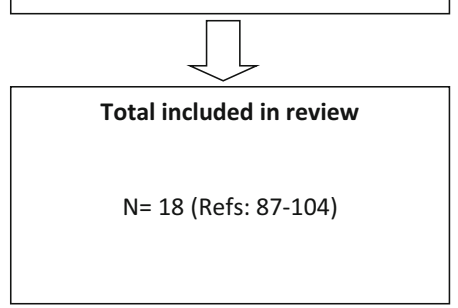

Fig. 1 (continued)

parameters was remarkably low (27 \%; Table 1) considering that the physics of light forms a fundamental basis of this therapeutic process. Even when light is measured, the methods employed are not always adequate to fully assess light properties; only $8 \%$ of articles reported a method that was capable of characterising the spectral (wavelength) light output [73-75, 80, 82, 102]. The most common light measurement method used power or energy meters (Table 1), which is obviously an improvement on nil measurement; however, these devices are known to have significant limitations, which is discussed in 'Photodiodes and power meters'.

Table 2 details the current state of light measurement and reporting of light parameters in LLLT studies where missing information does not allow for key parameters to be assessed. It is likely that these inadequacies are related to several factors that include expense of equipment, lack of expertise in
Excluded

1) Not relevant to LLLT/photobiomodulation $(\mathrm{N}=0)$

2) Review articles $(\mathrm{N}=12)$; Hypothesis $(\mathrm{N}=1)$; Editorials ( $\mathrm{N}=3$ );

3) Reviewed under LLLT search (duplicates): $(\mathrm{N}=7)$ Total $=\mathbf{2 3}$ equipment usage, poor appreciation of light properties and deficiencies of LLLT research standardisation. Consequently, this review continues by introducing fundamental concepts of light measurement and radiometric terms in attempt to explain their critical importance for LLLT research.

\section{Light: the basics}

Over recent centuries, units of measurement have been established for quantifying and reporting the multitude of parameters that describe the wavelength, irradiance and incident beam area, distribution and energy of light. These parameters have significance for LLLT research, and when used properly will fully describe the 'medicine' (the light source and its properties) and the 'dose' (the irradiation parameters/protocol) and will improve reproducibility and information between researchers, manufacturers and clinicians. 


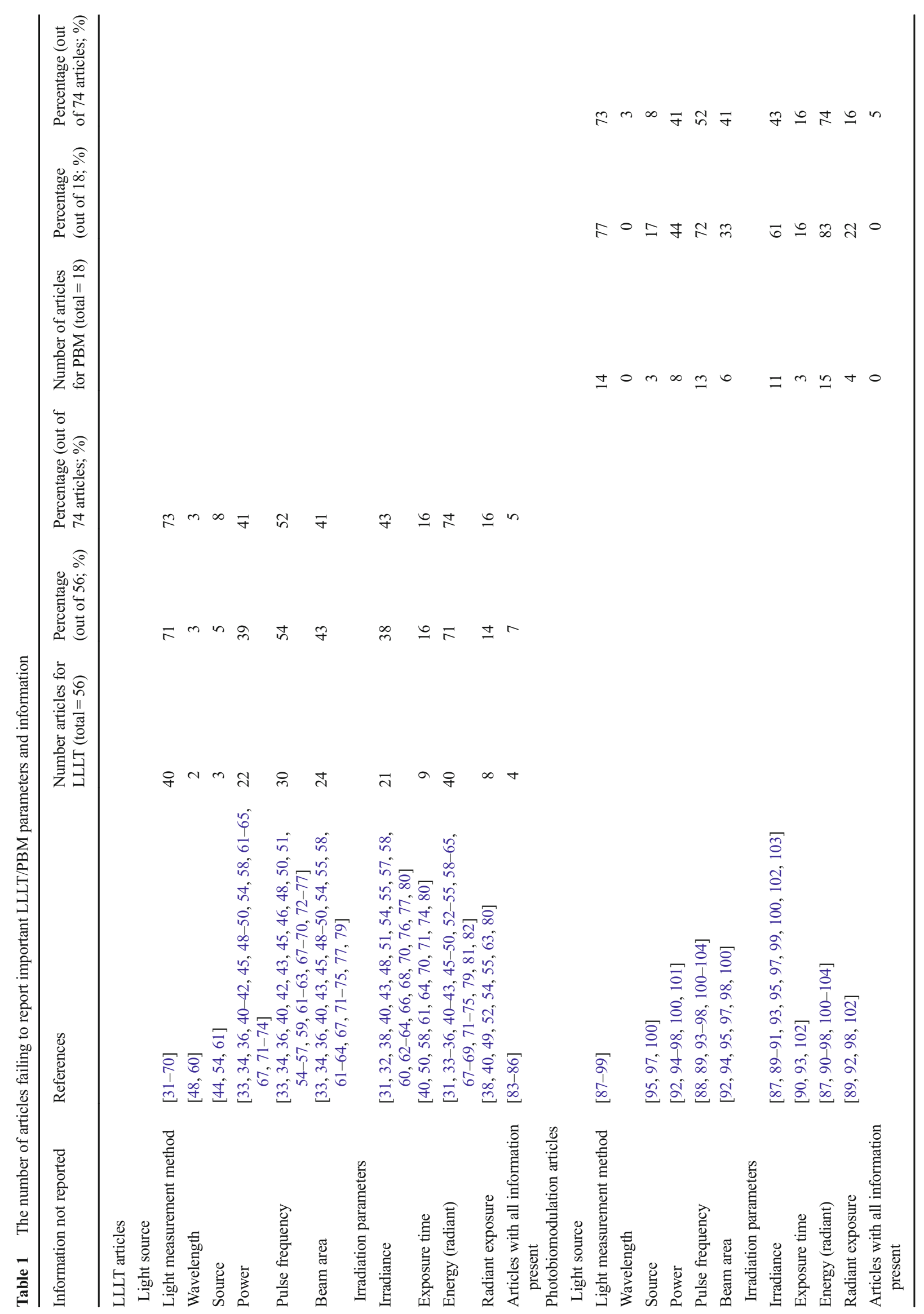




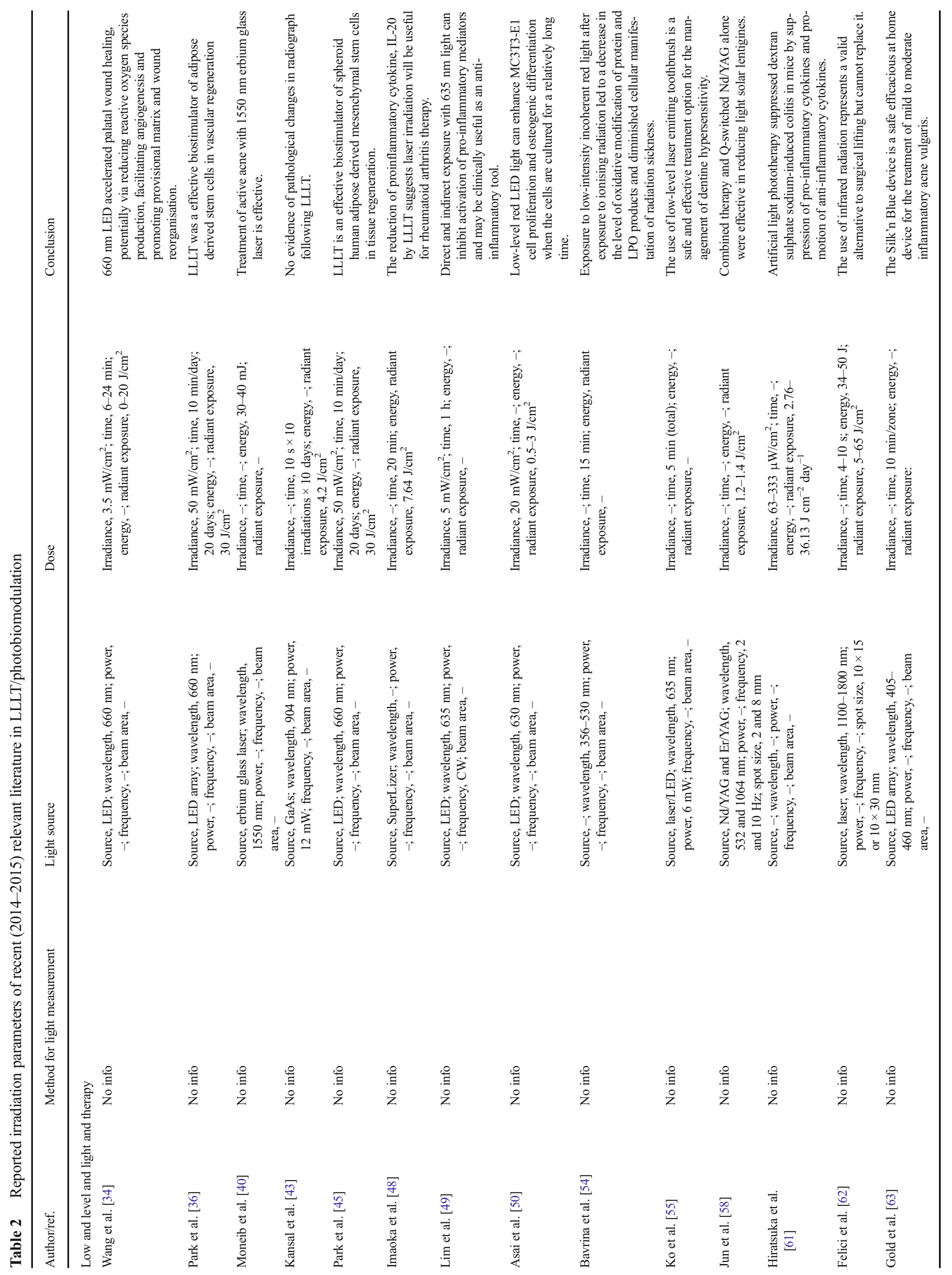



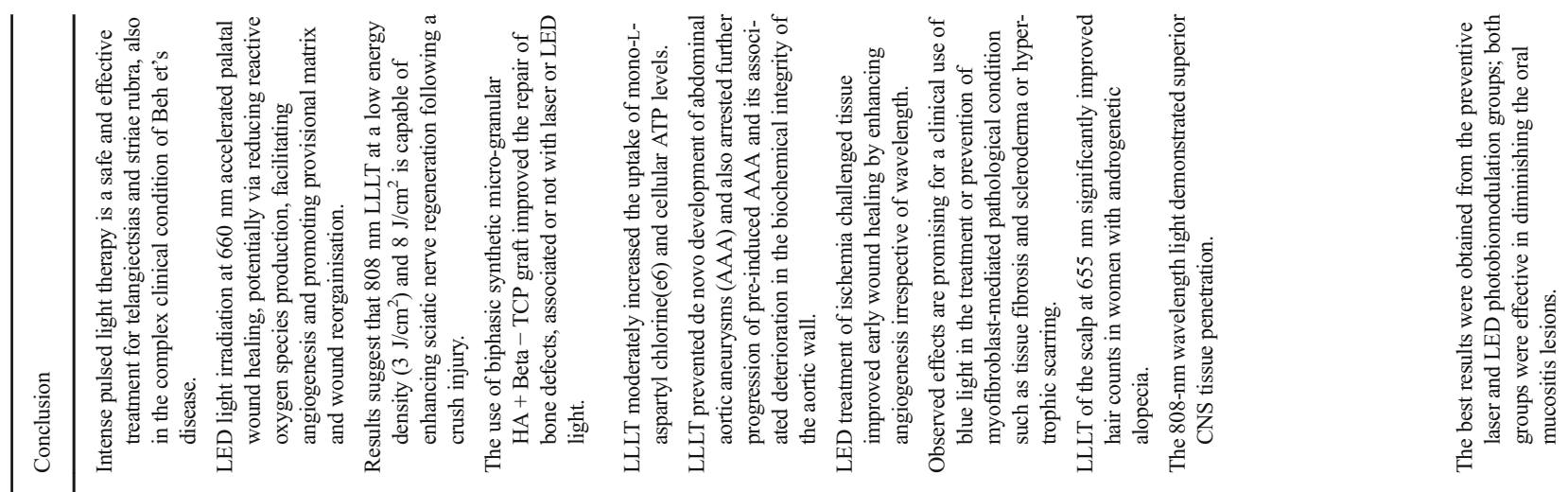

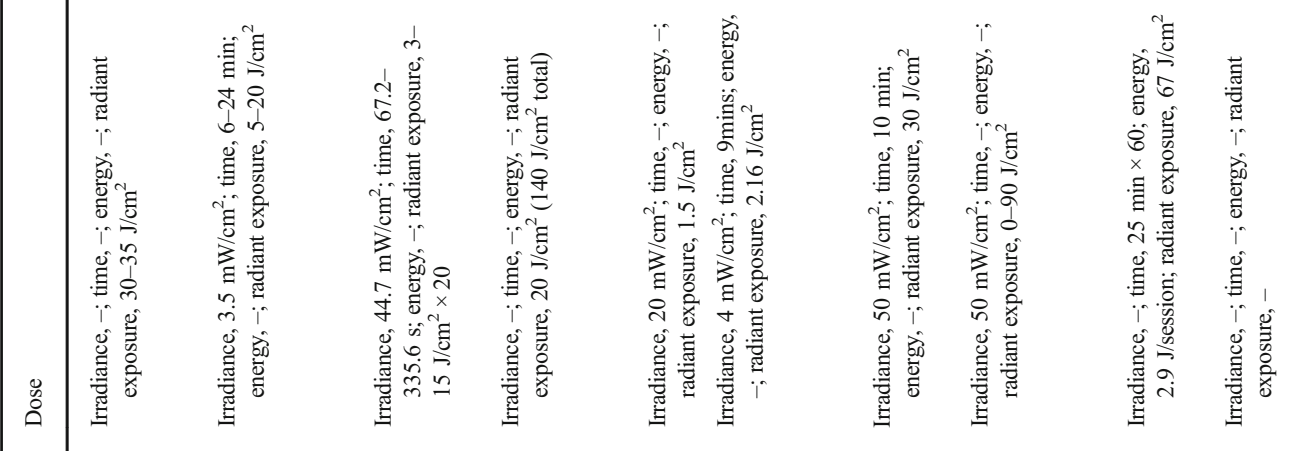

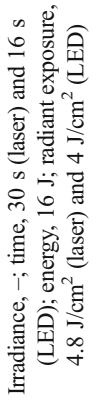

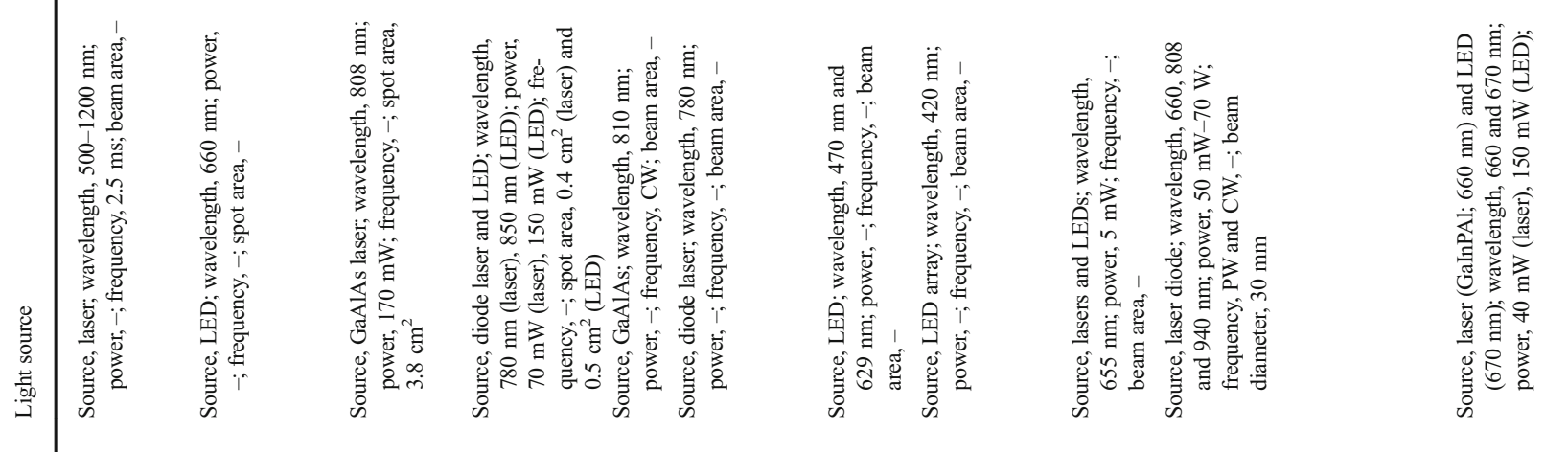
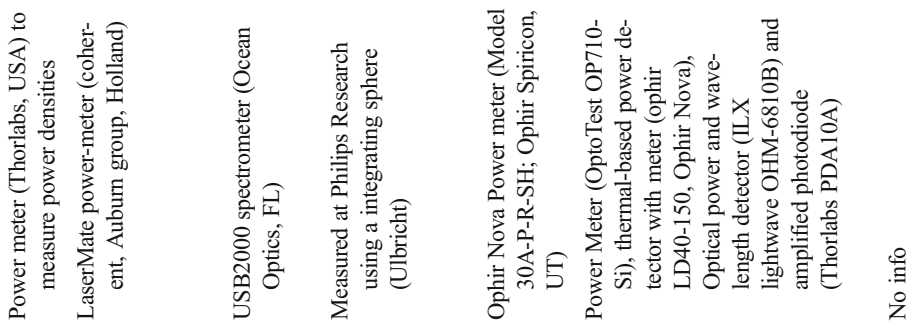


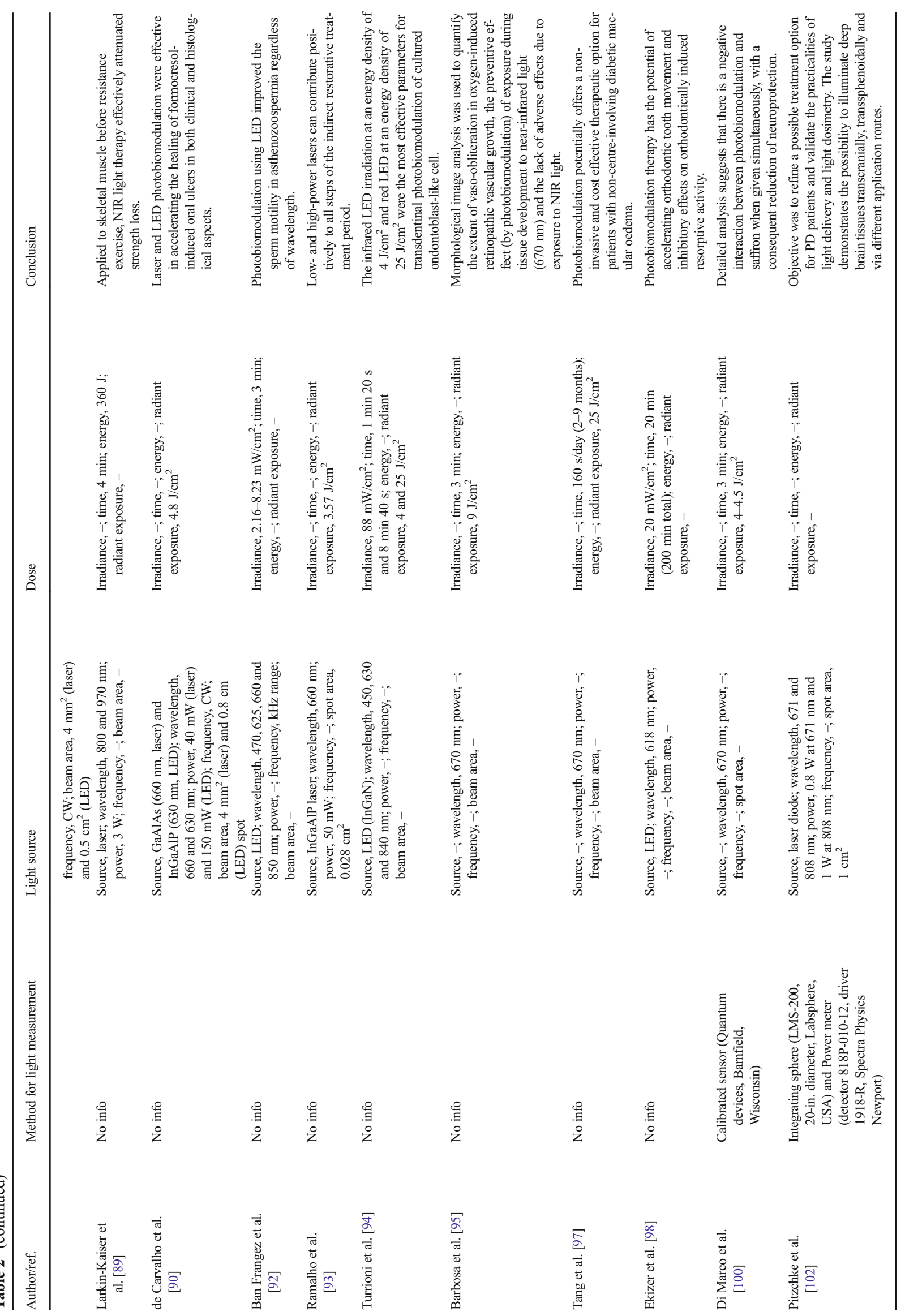




\section{Radiometry}

Radiometry is the measurement of electromagnetic radiation between approximately 10 and 1,000,000 nm. Within these wavelengths are the ultraviolet (UV; $<400 \mathrm{~nm})$, visible $(\sim 400-700 \mathrm{~nm})$, near-infrared $(\sim 700-1400 \mathrm{~nm})$ and infra-red (IR; >1400 nm) bands. Since LLLT experiments typically involve the application of light in the visible red and near-infrared region of the electromagnetic spectrum, radiometric terms should be employed to describe light properties and irradiation parameters that adequately depict key information needed for repeatable and reliable results between researchers, manufacturers and clinicians, which will ultimately improve clinical outcomes. Table 3 represents a summary of correct key terms, quantities and units that should be used in LLLT, although commonly incorrect terminology is stated. For example, studies will often report radiant exposure using the term energy density which actually describes a volumetric parameter rather than the amount of energy applied to a given area [66, 105-108] or use ambiguous terms such as intensity [108], which in radiometry can lead to confusion with 'radiant intensity' (the radiant power emitted, reflected, transmitted or received). Likewise, in LLLT, the term intensity does not distinguish whether the light is measured as 'radiant exitance' which is the amount of light leaving (emitted) from a surface, or 'irradiance' which is the amount of light arriving (irradiated) onto a surface; a subtle, yet critical consideration for accurate measurement of incident light at a specimen surface such as treated tissue or cell culture areas ('Irradiance and radiant exitance'). Another example of a commonly used, largely ambiguous term is spot-size $[39,62,91,103]$ and the errors that may arise in assuming a circular beam area, which may not be representative of an elliptical laser speckle pattern ('Beam area'). These ambiguous terms can potentially lead to misinterpretation of dosing parameters and poor reproducibility of data and should be avoided.

\section{Spectral quantities}

Radiometric quantities often have a spectral (or wavelength) variable. The spectral variable describes the distribution of these quantities with respect to their representative wavelengths: the total irradiance of a light source is defined by the irradiance at each individual wavelength. Spectral measurements are particularly important for chemical or biological applications, as the knowledge of spectral content is often vital in choosing or interpreting the effects of a particular light source. This is potentially critical as popular work by Karu [109] suggests light of appropriate wavelength is absorbed by copper complexes within the mitochondrial enzyme, cytochrome $c$ oxidase $(\mathrm{CCO})$, which then causes the release of bound nitric oxide leading to further downstream cell signalling effects [110, 111]. Therefore, there must be an effective spectral overlap between the absorption of CCO and laser/ LED emission for therapeutic LLLT. Consequently, not only is it important to characterise the spectral properties of the light source but also the absorbance profile of materials or tissue that can potentially absorb the therapeutic window of emitted light. It follows that accurate measurement and reporting of spectral information (peak wavelength, spectral irradiance, spectral half-width and absorption profiles) would confirm (or otherwise) the conclusions made in LLLT studies.

\section{Light, quantities, units and symbols}

\section{Radiant energy}

Electromagnetic radiation can be considered as both a wave and a particle (depending on how it is measured), which transports energy through space. This energy can be absorbed by physical objects and converted into other forms such as thermal or electrical energy (solar cells). For example, in photographic light meters, incident visible light causes electric current flow when the radiant light energy is transferred to electrons as kinetic energy, from which light power can be inferred
Table 3 Summary of quantities, symbols and units

\begin{tabular}{lllll}
\hline $\begin{array}{l}\text { Terminology commonly } \\
\text { used }\end{array}$ & Correct terminology & Symbol & Equation of relation & Unit \\
\hline Wavelength & Wavelength & $\lambda$ & & \\
Frequency & Pulse frequency & $\nu$ & $\mathrm{nm}$ \\
Radiant energy & Radiant energy & $Q$ & $\mathrm{~Hz}$ \\
Energy density & Not applicable & $u$ & $\mathrm{~J}$. & $\mathrm{J} \mathrm{d} t$ \\
Energy density/fluence & Radiant exposure /(radiant) fluence & $H$ & $\mathrm{~J} / \mathrm{cm}^{3}$ \\
Power (flux) & Power/radiant flux) & $\Phi$ & $\mathrm{d} Q / \mathrm{d} t$ & $\mathrm{~J} / \mathrm{cm}^{2}$ \\
Spot size & Beam area & $A$ & & $\mathrm{Watt}, \mathrm{W}$ \\
Power density/intensity & Irradiance & $E$ & $\mathrm{~d} \varphi / \mathrm{d} A$ & $\mathrm{~cm}^{2}$ \\
Intensity & Radiant exitance & $M$ & & $\mathrm{~W} / \mathrm{cm}^{2}$ \\
Exposure time/duration & Exposure time/duration & $t$ & & $\mathrm{~W} / \mathrm{cm}^{2}$ \\
& & & $\mathrm{~s}$ \\
\hline
\end{tabular}


('Photodiodes and power meters'). Similarly, for LLLT, light is transferred to cells as radiant energy that modulates cellular responses via $\mathrm{CCO}$ absorption and is analogous to photosynthesis, whereby the action of light, and light alone, directly stimulates cell responses. Whilst radiant energy is important [112], the parameter alone is not enough to determine treatment efficacy since an infinite combination of irradiance and exposure could lead to similar radiant energies. Radiant energy is denoted as $Q$ and expressed in Joules (J). Spectral radiant energy accounts for monochromatic (such as a single wavelength laser) and polychromatic sources (for example, lights which emit over a range of wavelengths) and is defined as radiant energy per unit wavelength interval at wavelength, $\lambda$ :

$Q_{\lambda}=\frac{d Q}{d \lambda}$

The units of spectral radiant energy are Joules per nanometre $(\mathrm{J} / \mathrm{nm})$

\section{Radiant flux or radiant power}

'Flux' or 'power' describes the time rate of flow of radiant energy. This is a parameter that is usually reported within LLLT literature through manufacturers' information or measured using power/energy meters (Tables 1 and 2). Metaphorically, this describes the 'potency' of the light and although important, does not provide adequate information concerning spectral and spatial distribution of the energy or the actual irradiance delivered to the target site. Lack of spatial information assumes uniform irradiance over the output area $[113,114]$, which can be far from accurate, especially considering the true irradiance across an active beam area (Fig. 2). This may differ according to the type of light source, e.g. the common elliptical profile of lasers (Fig. 2b) or the non-unform irradiance distribution of LEDs (Fig. 2c) and the distance from the light tip to the target area. Although power or radiant flux should be reported, it only partially describes irradiation parameters that are necessary for complete information relevant to LLLT research. Radiant power or flux has units of Joules per second $(\mathrm{J} / \mathrm{s})$ or watts $(\mathrm{W})$ and is defined as:

$\phi=\frac{d Q}{d t}$

The radiant flux per unit wavelength interval at wavelength, $\lambda$ is given the term spectral radiant flux and is defined as:

$\phi_{\lambda}=\frac{d \phi}{d \lambda}$

and measured in watts per nanometre $(\mathrm{W} / \mathrm{nm})$.

\section{Beam area}

Beam area is often referred to as 'spot-size' in the LLLT literature $[39,62,91,103]$. However, the term beam area should be preferred over spot-size and reported in square centimetres. The term spot is usually descriptive of a circular shape and size is ambiguous although units may remove ambiguity. As mentioned previously, lasers may emit an elliptical beam, which would significantly affect the area calculation (Fig. 2) and lead to misinterpretation of irradiation parameters. In cases where the beam area is non-circular, or of circular Gaussian, the beam area and/or diameter can be accurately determined using techniques such as beam profilometry which will be discussed in 'Light measurement/detectors'. Nonetheless, this review finds that a significant number of LLLT studies fail to report beam area (Tables 1 and 2), a key parameter that should be reported in all LLLT studies.

The radiant beam area acting on a target site is likely to significantly influence biological response in both in vivo, in vitro and clinical studies. Although systemic and local responses to LLLT irradiation have been reported [115] in vivo, beam area is also important for dosing and radiometric calculations. In vitro, a localised effect of light irradiation is likely to result in a significant biological response. Consequently, if the beam area is much smaller than the target culture area, then only a proportion of the host cells will be irradiated, attenuating the measured biological response and possibly resulting in a false-negative result. Therefore, a suggested good practice would be to ensure the whole culture well is irradiated evenly with a round, flat top beam.

\section{Irradiance and radiant exitance}

The radiant flux per unit area received by a surface from any direction can be termed irradiance (Fig. 3a). However, sometimes this is confusingly termed power density or intensity in the LLLT literature, and this does not distinguish between irradiance or light arriving (irradiance) or that leaving a surface (exitance). Irradiance is defined as:

$E=\frac{d \phi}{d A}$

where $d \phi$ is the radiant flux and $d A$ is differential area. The measured flux can also be that leaving the surface from any direction due to emission and/or reflection (Fig. 3b) and is given the term radiant exitance and defined as:

$M=\frac{d \phi}{d A}$

where $d \phi$ is the radiant flux leaving and $d A$ is differential area where $d \phi$ is leaving from. A possible use of this terminology in LLLT could be to describe reflection off biological tissue 
Fig. 2 Examples of spatial

distribution of irradiance in lasers and LED lights where the highest to lowest irradiance is represented by the rainbow colours, red to violet, respectively, for a $660 \mathrm{~nm}$ laser, b $810 \mathrm{~nm}$ laser and $\mathbf{c}$ $810 \mathrm{~nm}$ LED
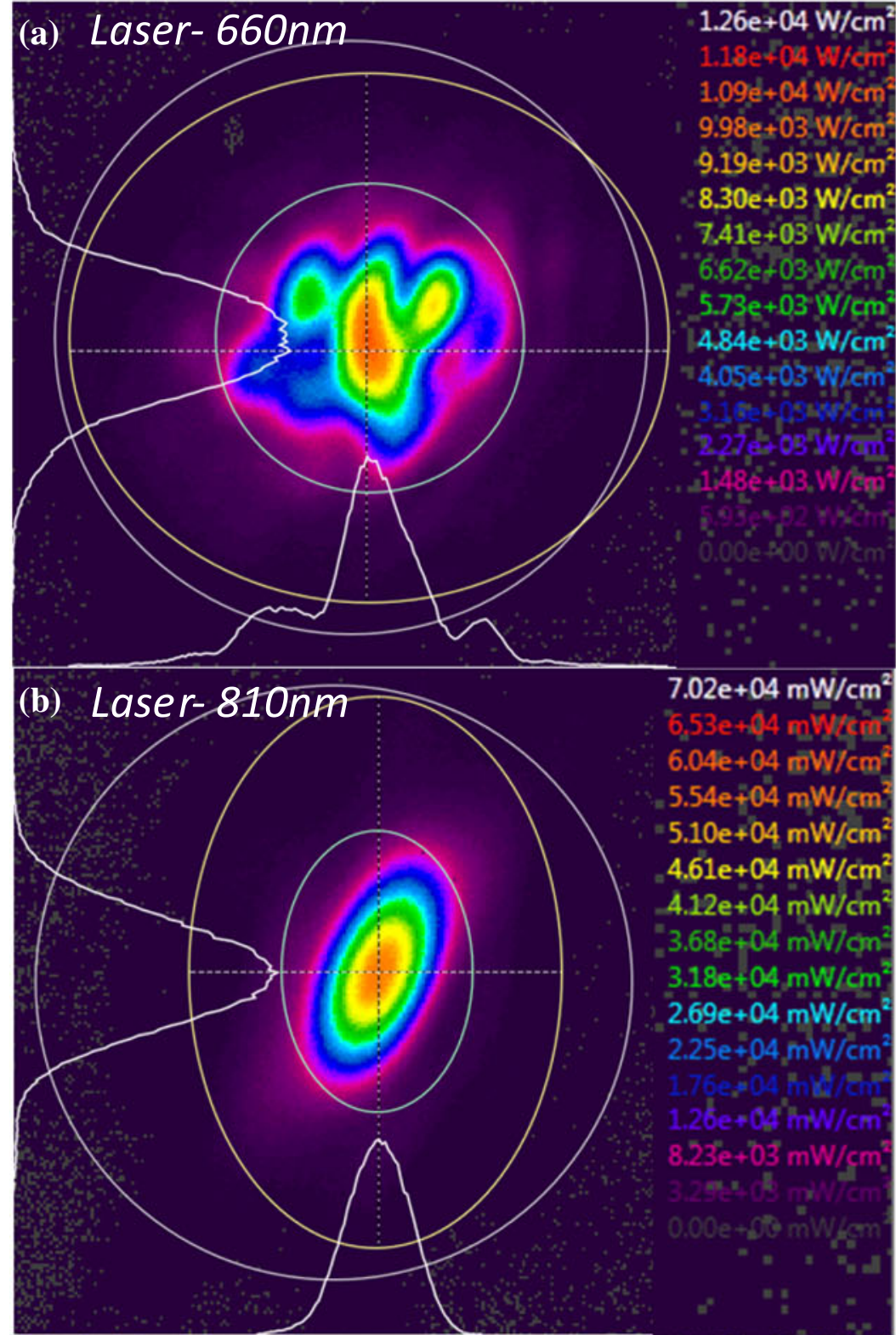

$7.02 \mathrm{e}+04 \mathrm{~mW} / \mathrm{cm}^{2}$ $6,53 \mathrm{e}+44 \mathrm{~mW} / \mathrm{kr}$ $6.04 \mathrm{e}+04 \mathrm{~mW} / \mathrm{cm}^{3}$ $5.54 \mathrm{e}+04 \mathrm{~mW} / \mathrm{cm}^{2}$ $5.10 \mathrm{e}+04 \mathrm{~mW} / \mathrm{cm}^{2}$ $4.61 \mathrm{e}+04 \mathrm{~mW} / \mathrm{cm}^{2}$ $4.12 \mathrm{e}+04 \mathrm{~mW} / \mathrm{cm}^{2}$ $3.68 \mathrm{e}+04 \mathrm{~mW} / \mathrm{cm}^{2}$ $3.18 \mathrm{e}+04 \mathrm{~mW} / \mathrm{cm}^{2}$ $2.69 \mathrm{e}+04 \mathrm{~mW} / \mathrm{cm}^{2}$ $2.25 \mathrm{e}+04 . \mathrm{mW}^{\mathrm{cm}} \mathrm{cm}^{2}$

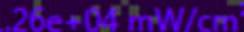
$3.23 \mathrm{e}+03 \mathrm{~mW} / \mathrm{cm}^{\mathrm{s}}$ axpras wher $100 \mathrm{e}+90 \mathrm{~mW}$ (S) c.

(c) LED-810nm

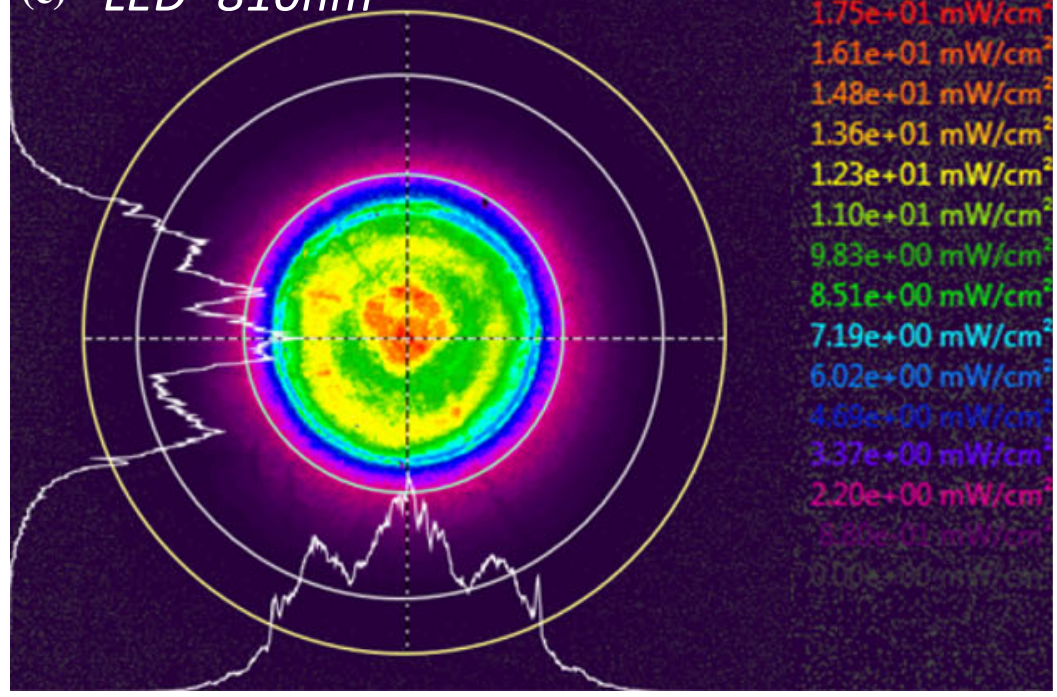

$188 \mathrm{e}+01 \mathrm{~mW} / \mathrm{cm}^{2}$

$1.88 \mathrm{e}+01 \mathrm{~mW} / \mathrm{cm}$

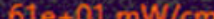
$148 \mathrm{e}+01 \mathrm{~mW} / \mathrm{cm}$ $1.36 \mathrm{e}+01 \mathrm{~mW} / \mathrm{cm}$ $1.23 \mathrm{e}+01 \mathrm{~mW} / \mathrm{cm}^{2}$ $1.10 \mathrm{e}+01 \mathrm{~mW} / \mathrm{cm}$ 
Fig. 3 The definitions of radiant flux density arriving (a irradiance) or leaving (b exitance) a surface (the lines represent rays of light travelling in the direction of the arrow)

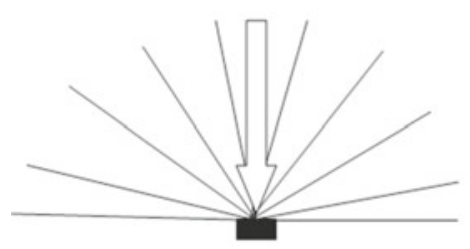

(a): Irradiance

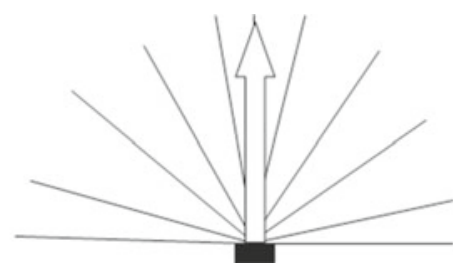

(b): Exitance such as dentine, bone and other tissues.

Irradiance can be measured in space and is usually measured in watts per square centimetre. This includes the surfaces of physical objects, i.e. tissue or cell culture samples, and the space occupied between them, i.e. air or through tissue thickness. This is particularly important when characterising lights that are highly divergent, as found in typical LED sources, or through tissue which is highly scattering.

Commonly, irradiance is not verified by researchers and only reported from manufacturers' quoted values or is calculated using values gained from inadequate measurement tools (Tables 1 and 2). Manufacturers' values are typically measured at the aperture or fibre tip, but because the beams are highly divergent, they are not useful for studies where the beam may be projected to a target such as in an in vitro study. Manufacturers' specific methods of measurement are also rarely divulged. Irradiation, in vivo or in in vitro cultures, likely occurs through tissue or culture plastics at distances greater than $0 \mathrm{~mm}$. Therefore, replicating and measuring key light parameters at, or through, relevant targets at specific distances and geometry is far more accurate and clinically and experimentally relevant than using manufacturers' data alone.

Spectral irradiance is the radiant flux per unit wavelength interval at wavelength $\lambda$ and can be defined for both irradiance and radiant exitance with the following equations:

$$
\begin{aligned}
& E_{\lambda}=\frac{d E}{d \lambda} \\
& M_{\lambda}=\frac{d M}{d \lambda}
\end{aligned}
$$

Spectral irradiance is measured in watts per square centimetre per nanometre.

\section{Exposure duration}

Although the most straightforward irradiation parameter to measure, exposure time $(s)$ is not always reported in the literature. Sixteen per cent $(12 / 74)$ of articles reviewed in this study failed to report exposure duration (Tables 1 and 2), which is likely due to a common misconception that wavelength, flux (radiant energy) and fluence are all that are necessary to replicate a successful treatment [29]. Exposure duration is a key component of 'dose', which is the product of irradiance and exposure time and should always be separately defined (Section 'Radiant exposure and exposure reciprocity').

In addition to reporting exposure time, when multiple exposures are performed, the number of treatment sites, the number of exposures and the interval between exposures should also be reported in order to fully describe the treatment protocol $[29,30]$.

\section{Radiant exposure and exposure reciprocity}

The energy delivered per unit area of cells during light stimulation for LLLT is also an important parameter since the efficacy of the treatment would depend on the irradiance delivered over a given area. The quantity areal, measured in joules per square centimetre and is often incorrectly termed energy density, should only be used for volumetric energy deposition $\left(\mathrm{J} \mathrm{cm}^{-3}\right)$. The proper terminology for the total amount of energy delivered per unit area is 'radiant exposure', or more commonly termed fluence in the LLLT literature, where $H$ (the radiant exposure or fluence) is defined as the integral of the irradiance from Eq. 4

$H=\int_{0}^{T} E d t$

However, many researchers merely quote radiant exposure (sic. energy density) as an expression of dose within the literature with missing irradiance $\left(\mathrm{W} / \mathrm{cm}^{2}\right)$ or exposure duration (s) values (or even both; Tables 1 and 2). This is potentially unreliable, as it assumes an inverse correlation between the effects of irradiance and exposure duration.

The Bunsen-Roscoe 'Law of Reciprocity' states that photochemical reactions will be independent of irradiance and exposure time with the effects being directly proportional to the total energy delivered [116-118]. Although it can be assumed that this law is valid for photochemical reactions within a certain dose range, photobiological responses of cells and tissue usually involve a sequence of interacting biological reactions making a linear dose-time relationship less likely. A true reciprocal relationship between irradiance and time would achieve similar therapeutic effects regardless of how radiant exposure was achieved (e.g. $20 \mathrm{~s}$ at $100 \mathrm{~mW} / \mathrm{cm}^{2}$ would exhibit similar therapeutic effects compared with $200 \mathrm{~s}$ at 
$10 \mathrm{~mW} / \mathrm{cm}^{2}$ or $80 \mathrm{~s}$ at $25 \mathrm{~mW} / \mathrm{cm}^{2}$ ). However, although an effective radiant exposure for a specific cell type is an important, and a largely unknown quantity in LLLT, the individual parameters (irradiance and time) are critical and should also be defined. Notably, if the irradiance is too low and/or the delivery time too short, any significant beneficial effect may not be realised or even reduced [19, 81]. Furthermore, if the irradiance is too high or the irradiation time is too long, any significant benefit may also be attributed to heat, or even sometimes produce inhibitory, rather than therapeutic effects [19, 68]. Thus, any useful concept of exposure reciprocity may not be applicable in biological systems such as LLLT, since treatment modalities may only be effective within a window of specific irradiation parameters [19]. However, using similar radiant exposure by varying the combination of irradiance and time, and its effect on stimulatory/inhibitory cell responses is not fully understood and warrants a systematic approach to further understanding of the photobiomodulation of different cell types.

\section{Pulse frequency}

The pulse frequency is the number of pulses of a repeating signal in a specific time frame and is usually measured pulse per second $(\mathrm{Hz})$, thus pulse operation of lasers or LEDs is not classified as a continuous wave. This type of operation is beneficial for heat dissipation and to achieve high peak irradiances, but since there is an on/off period, dosing parameters such as radiant energy and radiant exposure are affected which may affect the efficacy of LLLT [52, 64, 68]. For example, if the irradiation was pulsed to deliver light at $0.5 \mathrm{~s}$ intervals, then only half the energy would be delivered compared with continuous delivery at similar irradiance and exposure time. Thus, when pulsing regimes are utilised, the peak irradiance should be defined along with pulse frequency and the on/off durations as previously recommended [29, 30].

\section{Light measurement/detectors}

\section{Spectro(radio)meters}

A spectrometer is an instrument used to measure the properties of light over specific portions of the electromagnetic spectrum and provides a useful system to analyse spectral characteristics critical for LLLT research. Spectrometers are coupled with flexible, transparent optical fibres of varying diameters made from high-quality glass that function as waveguides or light guides to transmit light between the two fibre ends. Opaline cosine correctors are usually attached, which have diffusing material apertures allowing light measurement normal to its surface with $180^{\circ}$ field of view (Fig. 4a). Whilst cosine corrector probes provide a cheap, versatile, robust and reliable method of light measurement, the measurement accuracy is limited when analysing large light sources due to its small collection area and its $180^{\circ}$ field of view. Alternatively, integrating spheres of varying diameter and port size (dependent upon the source size) can be used, which consist of hollow spherical cavities covered with diffuse white reflective coating. Spheres can be used to capture and measure light radiated in all directions from the light source as light scattered by the interior of the integrating sphere is evenly distributed over all angles (Fig. 4b). However, measurements using integrating spheres are limited by the size of the sphere and the size of the light source intended to be measured. Nevertheless, the fibres and cosine corrector (or integrating sphere) collectively become an optical probe, which can be calibrated using a photometric standard or calibrated light source to National Institute of Standards and Technology (NIST) standards providing an accurate measurement system known as a spectroradiometer.

Light is captured through the cosine corrector or integrating sphere and travels through the optical fibre into the spectrometer. The core of the spectrometer is formed by a diffraction grating which splits radiant light into its spectral components and projects the diffracted elements onto a detector. Computer software is used to calculate all radiometric, photometric and colourimetric quantities from spectral data. Two types of spectrometers exist, an array type, which has a fixed diffraction grating and a detector array, and a scanning spectrometer, which has a single detector and a rotating diffraction grating (Fig. 4c). Spectrometers are popular light measurement systems for many aspects of photonics research although rarely used in LLLT studies (Table 2). However, there are other limitations of fibre-coupled spectrometers which use cosine correctors and integrating spheres, primarily that power uniformity within the incident beam is assumed and the power distribution of light across the exit diameter of large light sources cannot be measured [114]. For example, using a typical cosine corrector diameter of $4 \mathrm{~mm}$ to measure an incident beam diameter of $10 \mathrm{~mm}$, the outer $6 \mathrm{~mm}$ of the beam will not be captured by the sensor. Light sources used for LLLT typically have a Gaussian distribution and therefore if the irradiance is measured centrally, power is assumed to be equal over the whole area and the measured irradiance would be overestimated. Error is increased with the increasing ratio of beam diameter to probe diameter (or vice versa) and researchers need to cautiously interpret data in such situations. Ideally, researchers should employ methods that will adequately measure all of the light by considering the projected beam area on a target and the distance that the beam is applied from. For example, if LLLT studies are performed by irradiating culture dishes or tissue samples from a specific distance, then the experimental light measurement methods should simulate this to accurately analyse light properties at the target site (irradiance), i.e. measure light received by cells, not what the light outputs. The effects of absorption, scattering and 
(a)

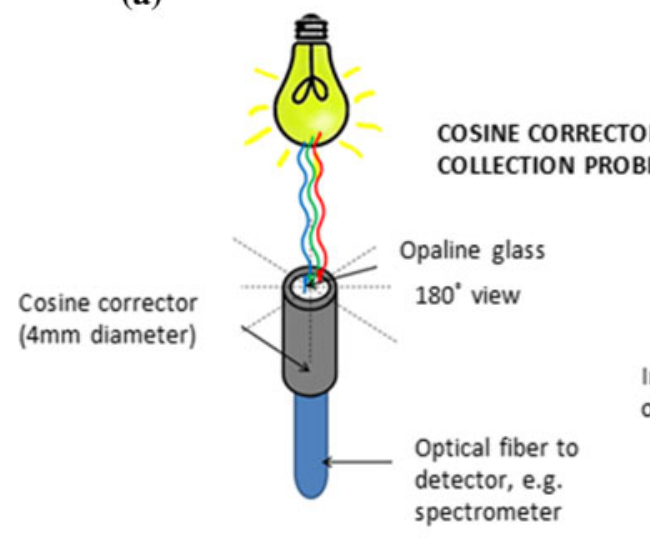

(b)

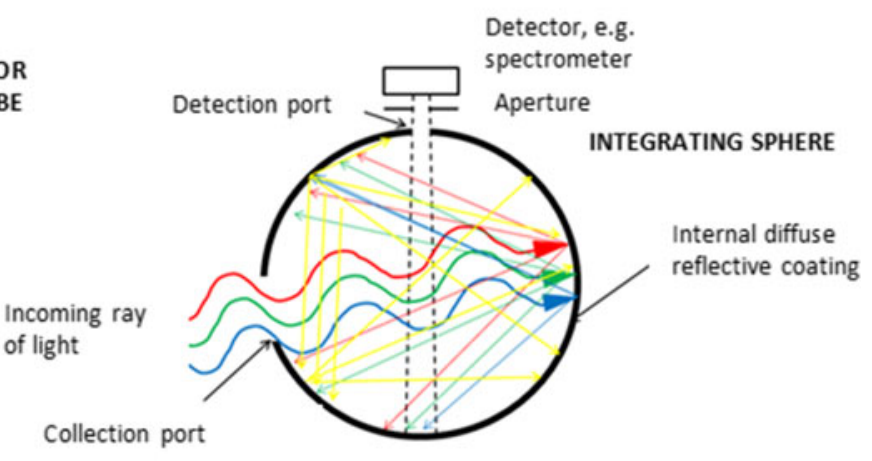

spectrometer

Collection port

(c)

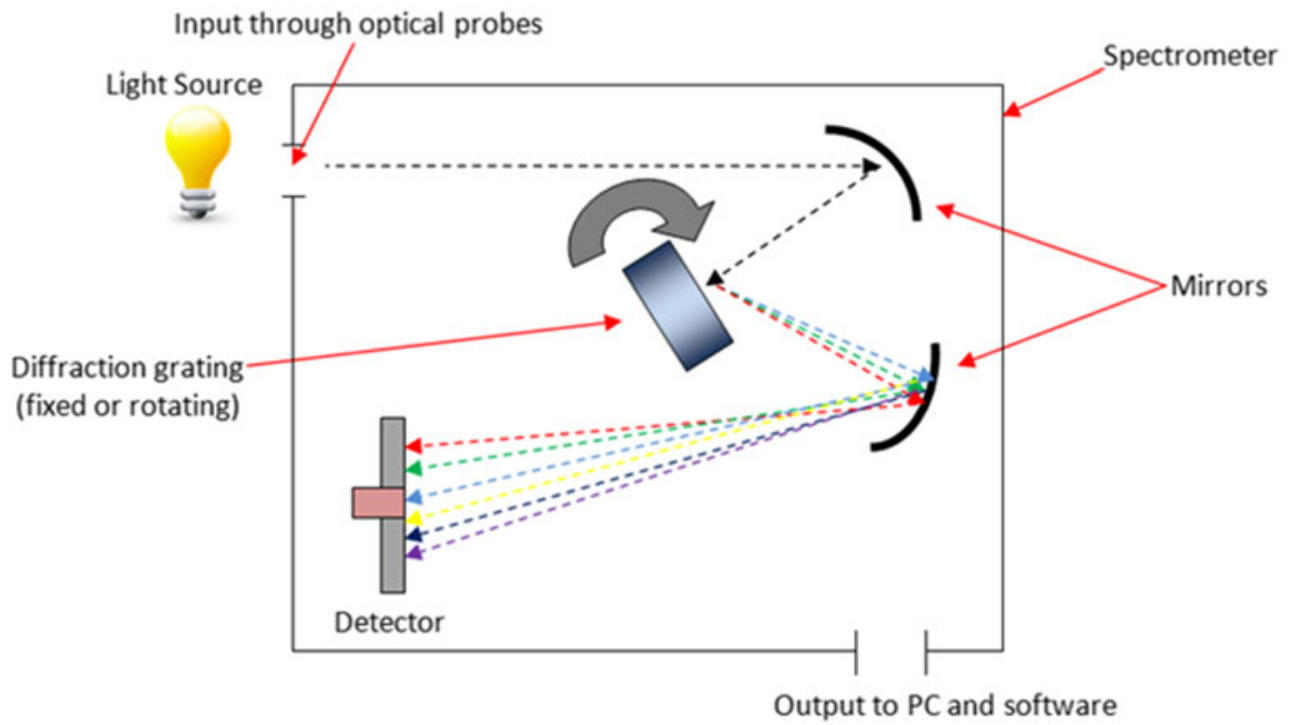

Fig. 4 Schematic representation of the internal workings of an a integrating sphere showing the $360^{\circ}$ collection of light; $\mathbf{b}$ a cosine corrector probe allowing a $180^{\circ}$ field of view; and $\mathbf{c}$ the internal workings of a UV-vis spectrometer

reflection by media, cell culture plasticware and other materials/tissue on spectral irradiance at the target site are critical and should be carefully considered, i.e. for cell culture work, the irradiance delivered on the culture area through plasticware should be measured to accurately determine the irradiance delivered to cells.

Spectrometers can also be used to measure absorption characteristics of specific cellular chromophores or photorecepetors localised in the mitochondria that are responsible for the absorption of light. A light source emitting multiple wavelengths is focused on to a sample which attenuates light through absorption, scattering and reflection of the incident light. The action spectra, a plot of relative effectiveness of different wavelengths, which is believed to mimic the absorption spectrum of $\mathrm{CCO}$, has been reported by Karu et al. [119] and indicates several effective bands relating to the copper complexes of CCO. Thus, by recording this attenuation of light for various wavelengths, an absorption spectrum can be obtained and potential therapeutic windows for LLLT can be identified for specific tissue.

\section{Photodiodes and power meters}

A photodiode (detector) is responsive to optical input from UV to near infrared radiation and operates as a photoelectric converter generating a current that is proportional to the incident light. A photon of sufficient energy creates an electron hole pair by a mechanism known as the inner photoelectric effect that is dependent upon the efficiency of the photodiode. Quantum efficiency is dependent upon many factors, but in general if the energy of the photon is greater than the energy gap of the device, these photons will be absorbed very near the surface where the recombination rate is high and will contribute to a photocurrent. Thus, the photocurrent produced by the photodiode is proportional to the power of the light which can be measured directly by a 'power meter' which uses an operational amplifier circuit known as a transimpedance amplifier.

Although this type of measurement system is most popular within LLLT literature (Table 1), measurements from these devices should be interpreted cautiously. The spectral 
Fig. 5 A 2D beam profile image of a LLLT laser device: a an image of the actual tip area used for light delivery, $\mathbf{b}$ the actual active beam area and the location of the beam within the fibre optic tip and $\mathbf{c}$ the laser 'speckle' beam pattern of the devices and its active beam diameter/area
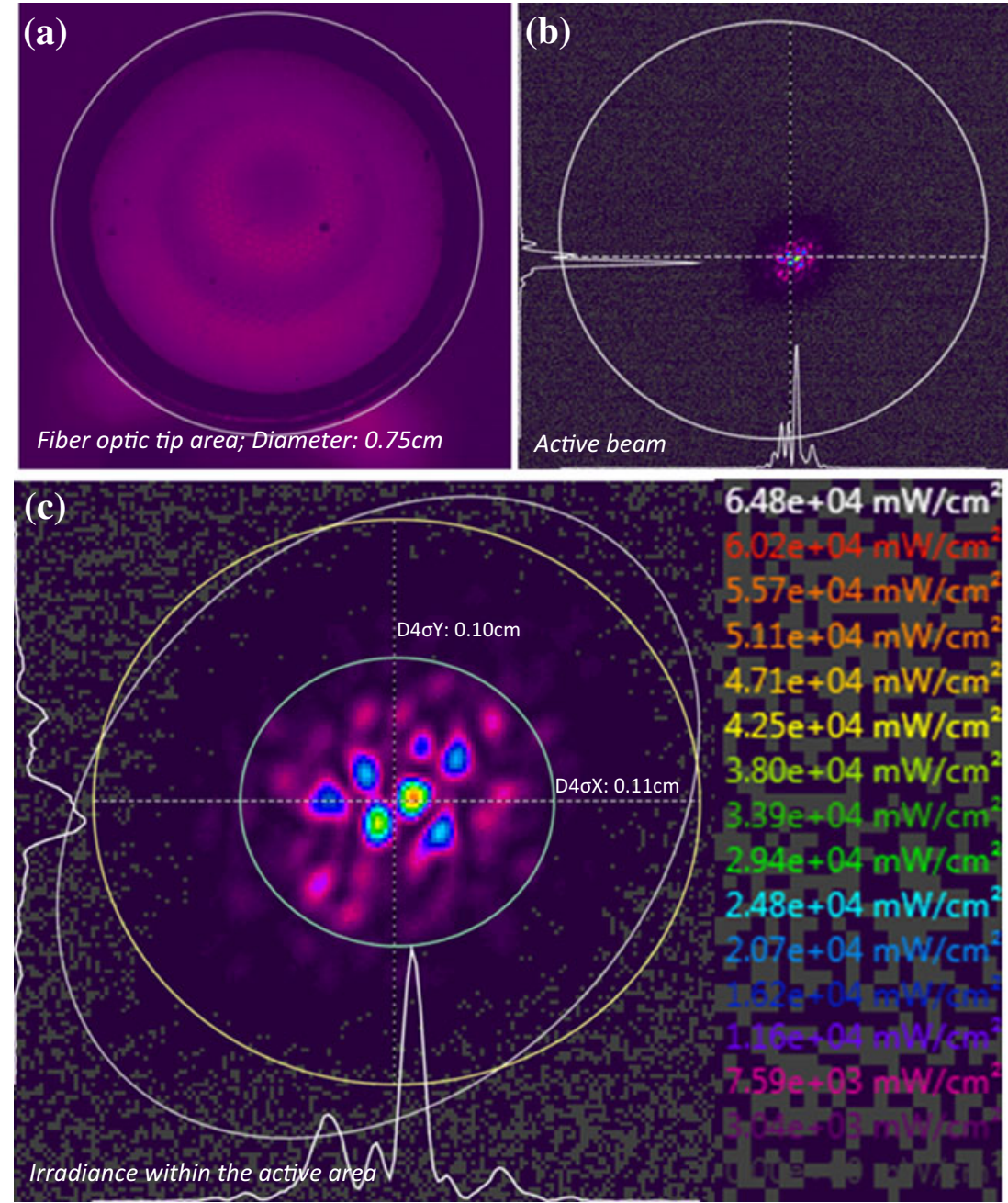

sensitivity differs with wavelength due to the quantum efficiency of the photodiode and generally has a better response at longer wavelengths. Thus, if broadband light sources are measured, the power emitted at short and longer wavelengths maybe be under- or over-estimated, respectively. Photodiodes also assume power uniformity across the beam and do not therefore effectively characterise the distribution of light for the same reasons described previously ('Spectro(radio)meters'). Although reproducible measurements can be made at the sub-picoampere regime, the response time is limited by the sensor size, which slows as surface area increases. Furthermore, the detectors are usually made from fragile or sensitive materials such as silicon $(\mathrm{Si}$; 190-1100 nm), germanium (Ge; 400-1700 nm), indium gallium arsenide (InGa; 800-2600 nm), lead(II) sulphide $(<1000-3500 \mathrm{~nm})$ or mercury cadmium telluride $(400$ $14000 \mathrm{~nm}$ ) which can be prone to damage and therefore measurements usually must be made without contact with the detector. Consequently, even small distances are likely to result in a loss of power due to divergence which will reduce the measured power. More so and unlike spectrometers, photodiodes do not provide spectral information and are usually only limited to power readings (W) and crude irradiance measurements $\left(\mathrm{W} / \mathrm{cm}^{2}\right)$ based on the sensor size or inputted tip or beam area values. However, photodiodes are relatively insensitive to temperature fluctuation (not critical for LLLT as low powered sources are used) and their main and unique advantage lies in their ability to measure very small optical powers which is specifically useful for basic light characterisation in LLLT studies.

\section{Thermopiles}

Thermopiles are essentially thermal sensors, which are best suited for measuring constant wave $(\mathrm{CW})$ laser power, average power in pulsed lasers or the energy of long pulses. Thermopiles are robust, reliable and are a well-established method to measure light energy. They can be considered as an array of miniature thermocouple junctions connected in series as differential pairs. These differential pairs make up cold and hot junctions that are connected by alternating ntype and p-type materials. Thermopiles operate by using 
temperature differences to create a voltage, which is correlated to the temperature gradient between the hot and cold junctions and proportional to the light energy. These systems are particularly useful for measuring high powered sources ( $>1$ Watt) which can damage other types of sensors. Thermopiles are made from materials such as antimony ( $\mathrm{Sb}$ ), bismuth (Bi), poly-silicon gold $(\mathrm{Au})$ or alumininium $(\mathrm{Al})$ and operate over a broad spectral range $(200-20000 \mathrm{~nm})$. Thermopiles tend to be more accurate than photodiodes but measurement sensitivity is reduced at low power. Since thermopiles work by using temperature gradients, they can be used to map irradiance distribution and offer uniform spatial response that is unaffected by changes in beam size, position or uniformity unlike photodiodes and spectrometer based systems which rely on inputted beam area values for irradiance calculation. However, although this type of sensor validly characterises the distribution of light and provides an accurate measure of important light properties such as irradiance and beam area, like the photodiode, it does not provide spectral information. Furthermore, response times are slow (generally a few seconds), which could be problematic in time-dependent experiments and thus are only really capable of measuring average powers. In addition, since the measurement is based on heat exchange, rapid fluctuations in housing temperature will decrease accuracy.

\section{Charge coupled device cameras and beam profilometry}

A charge coupled device (CCD) is an integrated circuit etched onto a silicon surface forming light sensitive elements called pixels. Photons incident on this surface generate charge that is converted into a digital copy of the light pattern. Following appropriate calibration, beam profilometry is very useful for characterisation and quantification of power distribution and irradiance of a given light source and has the advantages of both photodiodes (good response time and unaffected by temperature) and thermopiles (unaffected by beam diameter, good sensitivity and spatial distribution of power and irradiance, which can be used over a large range of power outputs). Light can be collected through lenses and directed onto the CCD sensor which then creates a digital image of the beam. Calibration using pre-determined power values may then be used to calculate the average power delivered to each pixel within the defined beam area to create a mapped irradiance image [120]. This is known as the top-hat factor and can be used to characterise the degree of spatial [114, 120-122] and spectral [123] uniformity of the power distribution. For system calibration, if the total measured power is calculated (using, for example, a photodiode or thermopile), the power received by each pixel in the detector's diode array can be calibrated to generate a 2- or 3-dimensional map of irradiance distribution across the active beam area. Therefore, the beam area can be accurately calculated rather than only measuring the light delivery tip diameter by crude methods such as calipers. For example, if the tip size of a LLLT laser device is much larger $(7.5 \mathrm{~mm}$ diameter) than the actual beam diameter $(\sim 0.11 \mathrm{~mm}$ diameter; Fig. 5), erroneous irradiance values are inevitably obtained if the active beam area is assumed to be the same as the tip diameter. Thus, the need for standardised beam area calculation is required in LLLT, preferably using the ISO standard method (D4 $\sigma$ or second moment width; ISO 111453.5 .2 [122]) or $1 / \mathrm{e}^{2}$ as suggested previously [29, 30].

Although CCD cameras and beam profilers are widely used for a variety of applications including dental research [114], this method has only been utilised in a limited number of LLLT studies [82, 120]. However, whilst beam profilers provide a relatively accurate measurement system, they are also unable to readily provide spectral information and are sensitive to spectral variation. Accurate and reliable test centres for LLLT research would have a suite of complimentary equipment including spectrometers or integrating spheres, photodiodes and beam profilers.

\section{Safety requirements for LLLT}

Whilst the perceivable dangers of LLLT are mainly related to retinal damage (both clinician and patient) and skin burn (mainly related to shorter UV wavelengths), the safety of LLLT is well documented in a number of standards such as US Code of Federal Regulations, American National Standards Institute and the International Standards Manual, and other laser safety books and review articles [21, 22]. This includes 'The Guidelines for Skin Exposure to Light' in the International Standards Manual (IEC-825) which states that an exposure of less than $200 \mathrm{~mW} / \mathrm{cm}^{2}$ is safe, and the marketing and the use of therapeutic LLLT is approved by the Food and Drug Administration. Preventative measures such as safety googles should always be utilised to minimise any risks and therapeutic devices may utilise high-powered light sources $(>500 \mathrm{~mW})$ may be spread over larger areas to fall within the recommended irradiance exposure limits. The operation of high-powered light sources may also be compensated by pulsing which may reduce the risk of any adverse effects caused by heating as discussed previously.

\section{Recommendations}

LLLT has generated markedly increasing interest in a wide variety of biomedical disciplines. However, researchers frequently report LLLT studies that have inadequate information regarding light properties and use ambiguous terminology. Thus, it is increasingly difficult to compare and contrast study outcomes, which hinders the progress in this field. Researchers working in LLLT should utilise a minimal set of 
standard criteria for light measurement and reporting of radiometric data that are necessary for a repeatable scientific study and are sufficient to compare and contrast study outcomes. These include ten key parameter: wavelength, power, irradiation time, beam area (at the skin or culture surface), radiant energy, radiant exposure, pulse parameters, number of treatments, interval between treatments and anatomical location, which will improve the information available to other researchers. A similar approach is utilised in other biomedical research areas such as mesenchymal stromal stem cell (MSC) research which has a set of standard criterion to foster a more uniform characterisation of MSC and facilitate better exchange of data among investigators [124].

The measurement of light is fundamentally important for LLLT research, thus researchers should not merely rely on manufacturers information which is what is reportedly routinely practiced in many LLLT studies (Tables 1 and 2). Instead, researchers should use a combination of complimentary methods that will accurately describe the ten key parameters previously mentioned. For example, to describe the spectral output of a light source, spectrometer-based systems should be used, improving accuracy by employing integrating spheres to capture all of the light rather than cosine correctors. Similarly, to describe spatial distribution of power and irradiance, beam profilers or thermopiles could be employed. Further, as good practice, light property information should be fully reported in a standardised form as recommended previously $[22,29]$. The terminology should also be consistent from study to study, which will make comparison and experimental repetition more straightforward. For example, instead of power density, the term irradiance should be used; instead of energy density, use radiant exposure or fluence, and so on (Table 3). Finally, the units should also be appropriately assigned, e.g. watts per square centimetre or milliwatts per square centimetre for irradiance depending on the output of the light source. Although these recommendations will probably require modification as new knowledge, technology and techniques unfold, they provide a minimal standard criteria that will facilitate a better exchange of information within LLLT which could 'drive' this field forward.

\section{Conclusions}

It is apparent that a relatively poor appreciation of radiometric properties exists within the literature associated with LLLT. Proper radiometric measurements are fundamental for this area of research and although it may appear straightforward, concepts and appropriate measurement techniques are commonly misunderstood, or ignored. Furthermore, the literature suffers greatly from missing information such as wavelength, power, pulse parameters, beam area, beam profile information, irradiance, exposure time, radiant exposure and evidence of calibrated measurement tools, making reliability questionable and reproducibility difficult all of which weakens the strength of conclusions potentially giving rise to false or nil results. The persistence of misunderstanding, inadequate experimentation and inaccurate reporting of radiometric data within LLLT literature has, and will continue to affect the reliability of LLLT information shared between scientists, manufacturers and clinicians. Ultimately, accurate measurements and reporting of light properties is essential to fully understand the potential beneficial biological mechanisms of LLLT, which could be achieved by following the recommendations of this review.

Acknowledgements This report is an independent research funded by the National Institute for Health Research (Invention for Innovation (I4I), Product Development Awards, II-LB-0712-20003). The views expressed in this publication are those of the author(s) and not necessarily those of the NHS, the National Institute for Health Research or the Department of Health.

Open Access This article is distributed under the terms of the Creative Commons Attribution 4.0 International License (http:// creativecommons.org/licenses/by/4.0/), which permits unrestricted use, distribution, and reproduction in any medium, provided you give appropriate credit to the original author(s) and the source, provide a link to the Creative Commons license, and indicate if changes were made.

\section{References}

1. Hopkins JT, McLoda TA, Seegmiller JG, Baxter DG (2004) Lowlevel laser therapy facilitates superficial wound healing in humans: a triple blind, sham controlled study. J Athl Train 39:226-229

2. Aimbire F, Albertini R, Pacheco MTT, Castro-Faria-Neto HC, Leonardo PSLM, Iversen VV, Martins L, Bjordal JM (2006) Low-level laser therapy induces dose-dependent reduction of $\mathrm{TNF} \alpha$ levels in acute inflammation. Photomed Laser Surg 24: 33-37

3. Stergioulas A (2004) Low-level laser treatment can reduce edema in second degree ankle sprains. J Clin Laser Med Surg 22:125128

4. Avci P, Gupta A, Sadasivam M, Vecchio D, Pam Z, Pam N, Hamblin MR (2013) Low-level laser (light) therapy (LLLT) in skin: stimulating, healing and restoring. Semin Cutan Med Surg 32:41-52

5. Brosseau L, Welch V, Wells G, Tugwell P, de Bie R, Gam A, Harman K, Shea B, Morin M (2000) Low level laser therapy for osteoarthritis and rheumatoid arthritis: a metaanalysis. J Rheum 27:1961-1969

6. Jackson Streeter (2001) Method for treating musculoskeletal injuries. US Patent $6267780 \mathrm{~B} 1$

7. Kneebone WJ (2006) Practical applications of low level laser therapy. Prac Pain Mangament

8. Xuan W, Vatansever F, Huang L, Wu Q, Xuan Y, Dai T, Ando T, Xu T, Huang Y-Y, Hamblin MR (2013) Transcranial low-level laser therapy improves neurological performance in traumatic brain injury mice: effect of treatment repetition regimen. PLoS One 8:e53454

9. Milward MR, Holder MJ, Palin WM, Hadis MA, Carroll JD, Cooper PR (2014) Low level light therapy (LLLT) for the 
treatment and management of dental and oral diseases. Dent Update 41:763-772

10. Bensadaun RJ, Nair RG (2012) Efficacy of low level laser therapy (LLLT) in oral mucositis: what we have learned from randomized studies and meta-analyses? Photomed Laser Surg 30:191-192

11. Umberto R, Claudia R, Gaspare P, Gianluca T, Alessandro DV (2012) Treatment of dentine hypersensitivity by diode laser: a clinical study. Int J Dent 2012:858950

12. Basso FG, Oliveira CF, Fontana A, Kurachi C, Bagnato VS, Spolidório DM, Hebling J, de Souza Cost CA (2011) In vitro effect of low-level laser therapy on typical oral microbial biofilms. Braz Dent J 22:502-510

13. Agrawal T, Gupta G, Rai V, Carroll J, Hamblin MR (2014) Pre conditioning with low-level laser (light) therapy: light before the storm. Dose Response 12:619-649

14. Tunér J, Hode L (1998) It's all in the parameters: a critical analysis of some well-known negative studies on low-level laser therapy. J Clin Laser Med Surg 16:245-248

15. Tunèr J and Hode L (2010) The new laser therapy handbook, chapter 13.1 - are all the negative studies really negative? Prima Books

16. Jang H, Lee H (2012) Meta-analysis of pain relief effects by laser irradiation on joint areas. Photomed Laser Surg 30:1-13

17. Tumilty S, Munn J, McDonough S, Hurley DA, Basford JR, Baxter GD (2009) Low level laser treatment of tendinopathy: a systematic review with meta-analysis. Photomed Laser Surg 00: $1-14$

18. Bjordal JM, Coupp CRT, Tun r J, Ljunggren EA (2003) A systematic review of low level laser therapy with location-specific doses for pain from chronic joint disorders. Aust J Physiother 49:107-116

19. Huang YY, Chen ACH, Carroll JD, Hamblin MR (2009) Biphasic dose response in low level light therapy. Dose Response 7:358 383

20. Ilic S, Leichliter S, Streeter J, Oron A, DeTaboada L, Oron U (2006) Effects of power densities, continuous and pulse frequencies, and number of sessions of low-level laser therapy on intact rat brain. Photomed Laser Surg 24:458-466

21. Sliney DH, Wolbarsht ML (1980) Safety with lasers and other optical sources: a comprehensive handbook. Plenum Press

22. Sliney DH (2007) Radiometric quantities and units used in photobiology and photochemistry: recommendations of the Commission Internationale de I'Eclairge (International Commission on Illumination. Photochem Photobiol 83:425-432

23. Tang E, Arany P (2013) Photobiomodulation and implants: implications for dentistry. J Periodontal Implant Sci 43:262-268

24. Rojas JC, Gonzalez-Lima F (2013) Neurological and psychological applications of transcranial lasers and LEDs. Biochem Pharmacol 86:447-457

25. Chung H, Dai T, Sharma SK, Huang YY, Carroll JD, Hamblin MR (2012) The nuts and bolts of low-level laser (light) therapy. Amm Biomed Eng 40:516-533

26. Peplow PV, Chung TY, Baxter GD (2010) Laser photobiomodulation of cells in culture: a review of human and animal studies. Photomed Laser Surg 28:S3-S40

27. Enwemeka CS (2011) The relevance of accurate comprehensive treatment parameters in photobiomodulation. Photomed Laser Surg 29:783-784

28. Hashmi JT, Huang YY, Osmani BZ, Sharma SK, Naeser MA, Hamblin MR (2010) Role of low-level laser therapy in neurorehabilitation. PM R 12:S292-S305

29. Jenkins PA, Carroll JD (2011) How to report low-level laser therapy (LLLT)/photomedicine dose and beam parameters in clinical and laboratory studies. Photomed Laser Surg 29:785-787
30. Stuck BE (1993) Measuring and reporting physical parameters in laser biomodulation research. SPIE 1883. Low-energy effects on biological systems. doi:10.1117/12.148024

31. Massotti FP, Gomes FV, Mayer L, de Oliveira MG, Baraldi CE, Ponzoni D, Puricelli E (2015) Histomorphometric assessment of the influence of low-level laser therapy on peri-implant tissue healing in the rabbit mandible. Photomed Laser Surg 33:123-128

32. Burger E, Mendes AC, Bani GM, Brigagão MR, Santos GB, Malaquias LC, Chavasco JK, Verinaud LM, de Camargo ZP, Hamblin MR, Sperandio FF (2015) Low-level laser therapy to the mouse femur enhances the fungicidal response of neutrophils against Paracoccidioides brasiliensis. PLoS Negl Trop Dis 9: e0003541

33. Park IS, Mondal A, Chung PS, Ahn JC (2015) Prevention of skin flap necrosis by use of adipose-derived stromal cells with lightemitting diode phototherapy. Cytotherapy 17:283-292

34. Wang CY, Tsai SC, Yu MC, Lin YF, Chen CC, and Chang PC (2015) $660 \mathrm{~nm}$ LED light irradiation promotes the healing of the donor wound of free gingival graft. J Periodontol 1-17

35. Dixit S, Agrawal PR, Sharma DK, Singh RP (2014) Closure of chronic non healing ankle ulcer with low level laser therapy in a patient presenting with thalassemia intermedia: case report. Indian J Plast Surg 47:432-435

36. Park IS, Mondal A, Chung PS, Ahn JC (2015) Vascular regeneration effect of adipose-derived stem cells with light-emitting diode phototherapy in ischemic tissue. Lasers Med Sci 30:533-541

37. Hwang MH, Shin JH, Kim KS, Yoo CM, Jo GE, Kim JH, Choi H (2015) Low level light therapy modulates inflammatory mediators secreted by human annulus fibrosus cells during intervertebral disc degeneration in vitro. Photochem Photobiol 91:403-410

38. Herpich CM, Leal-Junior EC, Amaral AP, Tosato Jde P, Glória IP, Garcia MB, Barbosa BR, El Hage Y, Arruda ÉE, Gomes CÁ, Rodrigues MS, de Sousa DF, de Carvalho PT, Bussadori SK, Gonzalez Tde O, Politti F, Biasotto-Gonzalez DA (2014) Effects of phototherapy on muscle activity and pain in individuals with temporomandibular disorder: a study protocol for a randomized controlled trial. Trials 15:491

39. de Brito Vieira WH, Bezerra RM, Queiroz RA, Maciel NF, Parizotto NA, Ferraresi C (2014) Use of low-level laser therapy $(808 \mathrm{~nm})$ to muscle fatigue resistance: a randomized double-blind crossover trial. Photomed Laser Surg 32:678-685

40. Moneib H, Tawfik AA, Youssef SS, Fawzy MM (2014) Randomized split-face controlled study to evaluate 1550 -nm fractionated erbium glass laser for treatment of acne vulgaris - an image analysis evaluation. Dermatol Surg 40:1191-1200

41. Derkacz A, Protasiewicz M, Rola P, Podgorska K, Szymczyszyn A, Gutherc R, Poręba R, Doroszko A (2014) Effects of intravascular low-level laser therapy during coronary intervention on selected growth factors levels. Photomed Laser Surg 32:582-587

42. Takhtfooladi MA, Shahzamani M, Takhtfooladi HA, Moayer F, Allahverdi A (2015) Effects of light-emitting diode (LED) therapy on skeletal muscle ischemia reperfusion in rats. Lasers Med Sci 30:311-316

43. Kansal A, Kittur N, Kumbhojkar V, Keluskar KM, Dahiya P (2014) Effects of low-intensity laser therapy on the rate of orthodontic tooth movement: a clinical trial. Dent Res J (Isfahan) 11: $481-488$

44. Xuan W, Agrawal T, Huang L, Gupta GK, and Hamblin MR (2014) Low-level laser therapy for traumatic brain injury in mice increases brain derived neurotrophic factor (BDNF) and synaptogenesis. J Biophotonics

45. Park IS, Chung PS, Ahn JC (2014) Enhanced angiogenic effect of adipose-derived stromal cell spheroid with low-level light therapy in hind limb ischemia mice. Biomaterials 35:9280-9289

46. Zigmond E, Varol C, Kaplan M, Shapira O, Melzer E (2014) Lowlevel light therapy induces mucosal healing in a murine model of 
dextran-sodium-sulfate induced colitis. Photomed Laser Surg 32: 450-457

47. Marques JM, Pacheco-Soares C, Da Silva NS (2014) Evaluation of the photobiomodulation in L929 cell culture. Exp Biol Med (Maywood) 239:1638-1643

48. Imaoka A, Zhang L, Kuboyama N, Abiko Y (2014) Reduction of IL-20 expression in rheumatoid arthritis by linear polarized infrared light irradiation. Laser Ther 23:109-114

49. Lim W, Choi H, Kim J, Kim S, Jeon S, Zheng H, Kim D, Ko Y, Kim D, Sohn H, Kim O (2015) Anti-inflammatory effect of $635 \mathrm{~nm}$ irradiations on in vitro direct/indirect irradiation model. J Oral Pathol Med 44:94-102

50. Asai T, Suzuki H, Kitayama M, Matsumoto K, Kimoto A, Shigeoka M, Komori T (2014) The long-term effects of red light-emitting diode irradiation on the proliferation and differentiation of osteoblast-like MC3T3-E1 cells. Kobe J Med Sci 60: E12-E18

51. Cunha MJ, Esper LA, Sbrana MC, de Oliveira PG, do Valle AL, de Almeida AL (2014) Effect of low-level laser on bone defects treated with bovine or autogenous bone grafts: in vivo study in rat calvaria. Biomed Res Int 2014:104230

52. Leal-Junior EC, Johnson DS, Saltmarche A, Demchak T (2014) Adjunctive use of combination of super-pulsed laser and lightemitting diodes phototherapy on nonspecific knee pain: doubleblinded randomized placebo-controlled trial. Lasers Med Sci 29: 1839-1847

53. Khoo NK, Shokrgozar MA, Kashani IR, Amanzadeh A, Mostafavi E, Sanati H, Habibi L, Talebi S, Abouzaripour M, Akrami SM (2014) In vitro therapeutic effects of low level laser at mRNA level on the release of skin growth factors from fibroblasts in diabetic mice. Avicenna J Med Biotechnol 6:113-118

54. Bavrina AP, Monich VA, Malinovskaya SL, Ermolaev VS, Druzhinin EA, Kuznetsov SS (2014) Correction of after effects of ionizing radiation by exposure to low-intensity light. Bull Exp Biol Med 156:663-664

55. Ko Y, Park J, Kim C, Park J, Baek SH, Kook YA (2014) Treatment of dentin hypersensitivity with a low-level laser-emitting toothbrush: double-blind randomised clinical trial of efficacy and safety. J Oral Rehabil 41:523-531

56. Aliodoust M, Bayat M, Jalili MR, Sharifian Z, Dadpay M, Akbari M, Bayat M, Khoshvaghti A, Bayat H (2014) Evaluating the effect of low-level laser therapy on healing of tentomized Achilles tendon in streptozotocin-induced diabetic rats by light microscopical and gene expression examinations. Lasers Med Sci 29:1495-1503

57. Führer-Valdivia A, Noguera-Pantoja A, Ramírez-Lobos V, SoléVentura P (2014) Low-level laser effect in patients with neurosensory impairment of mandibular nerve after sagittal split ramus osteotomy. Randomized clinical trial, controlled by placebo. Med Oral Patol Oral Cir Bucal 19:e327-e334

58. Jun HJ, Kim SM, Choi WJ, Cho SH, Lee JD, Kim HS (2014) A split-face, evaluator-blind randomized study on the early effects of Q-switched Nd:YAG laser versus Er:YAG micropeel in light solar lentigines in Asians. J Cosmet Laser Ther 16:83-88

59. Novaes RD, Gonçalves RV, Cupertino MC, Araújo BM, Rezende RM, Santos EC, Leite JP, Matta SL (2014) The energy density of laser light differentially modulates the skin morphological reorganization in a murine model of healing by secondary intention. Int $\mathrm{J}$ Exp Pathol 95:138-146

60. Hochman B, Pinfildi CE, Nishioka MA, Furtado F, Bonatti S, Monteiro PK, Antunes AS, Quieregatto PR, Liebano RE, Chadi G, Ferreira LM (2014) Low-level laser therapy and light-emitting diode effects in the secretion of neuropeptides SP and CGRP in rat skin. Lasers Med Sci 29:1203-1208

61. Hiratsuka T, Inomata M, Goto S, Oyama Y, Nakano T, Chen CL, Shiraishi N, Noguchi T, Kitano S (2014) Phototherapy with artificial light suppresses dextran sulfate sodium-induced colitis in a mouse model. J Gastroenterol Hepatol 29:749-756

62. Felici M, Gentile P, De Angelis B, Puccio L, Puglisi A, Felici A, Delogu P, Cervelli V (2014) The use of infrared radiation in the treatment of skin laxity. J Cosmet Laser Ther 16:89-95

63. Gold MH, Biron JA, Sensing W (2014) Clinical and usability study to determine the safety and efficacy of the Silk'n Blue Device for the treatment of mild to moderate inflammatory acne vulgaris. J Cosmet Laser Ther 16:108-113

64. Fioramonti P, Fino P, Ponzo I, Ruggieri M, Onesti MG (2014) Intense pulsed light in the treatment of telangiectasias: case report of Behçet's disease with superficial vascular involvement. J Cosmet Laser Ther 16:124-128

65. Huang YY, Nagata K, Tedford CE, Hamblin MR (2014) Lowlevel laser therapy $(810 \mathrm{~nm})$ protects primary cortical neurons against excitotoxicity in vitro. J Biophotonics 7:656-664

66. Ammar TA (2014) Monochromatic infrared photo energy versus low level laser therapy in patients with knee osteoarthritis. J Lasers Med Sci 5:176-182

67. Wang CY, Tsai SC, Yu MC, Lin YF, Chen CC, Chang PC (2015) Light-emitting diode Irradiation promotes donor site wound healing of the free gingival graft. J Periodontol 86:674-681

68. Leite SN, Andrade TA, Masson-Meyers Ddos S, Leite MN, Enwemeka CS, Frade MA (2014) Phototherapy promotes healing of cutaneous wounds in undernourished rats. An Bras Dermatol 89:899-904

69. Wang CZ, Chen YJ, Wang YH, Yeh ML, Huang MH, Ho ML, Liang JI, Chen CH (2014) Low-level laser irradiation improves functional recovery and nerve regeneration in sciatic nerve crush rat injury model. PLoS One 13:e103348

70. Pinheiro AL, Soares LG, Marques AM, Aciole JM, de Souza RA, Silveira L Jr (2014) Raman ratios on the repair of grafted surgical bone defects irradiated or not with laser $(\lambda 780 \mathrm{~nm})$ or LED ( $\lambda 850 \mathrm{~nm})$. J Photochem Photobiol B 138:146-154

71. Tsai SR, Yin R, Huang YY, Sheu BC, Lee SC, Hamblin MR (2015) Low-level light therapy potentiates NPe6-mediated photodynamic therapy in a human osteosarcoma cell line via increased ATP. Photodiagn Photodyn Ther 12:123-130

72. Gavish L, Beeri R, Gilon D, Rubinstein C, Berlatzky Y, Bulut A, Reissman P, Gavish LY, Gertz SD (2014) Arrest of progression of pre-induced abdominal aortic aneurysm in apolipoprotein Edeficient mice by low level laser phototherapy. Lasers Surg Med 46:781-790

73. Dungel P, Hartinger J, Chaudary S, Slezak P, Hofmann A, Hausner T, Strassl M, Wintner E, Redl H, Mittermayr R (2014) Low level light therapy by LED of different wavelength induces angiogenesis and improves ischemic wound healing. Lasers Surg Med 46: 773-780

74. Taflinski L, Demir E, Kauczok J, Fuchs PC, Born M, Suschek CV, Opländer C (2014) Blue light inhibits transforming growth factor$\beta 1$-induced myofibroblast differentiation of human dermal fibroblasts. Exp Dermatol 23:240-246

75. Teuschl A, Balmayor ER, Redl H, van Griensven M, Dungel P (2015) Phototherapy with LED Light modulates healing processes in an in vitro scratch-wound model using 3 different cell types. Dermatol Surg 41:261-268

76. Nadur-Andrade N, Dale CS, Santos AS, Soares AM, de Lima CJ, Zamuner SR (2014) Photobiostimulation reduces edema formation induced in mice by Lys-49 phospholipases A2 isolated from Bothrops moojeni venom. Photochem Photobiol Sci 13:15611567

77. Lanzafame RJ, Blanche RR, Chiacchierini RP, Kazmirek ER, Sklar JA (2014) The growth of human scalp hair in females using visible red light laser and LED sources. Lasers Surg Med 46:601607 
78. Panhoca VH, de Fatima Zanirato Lizarelli R, Nunez SC, Pizzo RC, Grecco C, Paolillo FR, Bagnato VS (2015) Comparative clinical study of light analgesic effect on temporomandibular disorder (TMD) using red and infrared led therapy. Lasers Med Sci 30: 815-822

79. Ferraresi C, de Sousa MV, Huang YY, Bagnato VS, Parizotto NA, Hamblin MR (2015) Time response of increases in ATP and muscle resistance to fatigue after low-level laser (light) therapy (LLLT) in mice. Lasers Med Sci 30:1259-1267

80. Tedford CE, DeLapp S, Jacques S, Anders J (2015) Quantitative analysis of transcranial and intraparenchymal light penetration in human cadaver brain tissue. Lasers Surg Med 47:312-322

81. Ferraresi C, Kaippert B, Avci P, Huang YY, de Sousa MV, Bagnato VS, Parizotto NA, Hamblin MR (2015) Low-level laser (light) therapy increases mitochondrial membrane potential and ATP synthesis in $\mathrm{C} 2 \mathrm{C} 12$ myotubes with a peak response at 36 h. Photochem Photobiol 91:411-416

82. Burland M, Paris L, Quintana P, Bec JM, Diouloufet L, Sar C, Boukhaddaoui H, Charlot B, Braga Silva J, Chammas M, Sieso V, Valmier J, and Bardin F (2014) Neurite growth acceleration of adult dorsal root ganglion neurons illuminated by low-level light emitting diode light at $645 \mathrm{~nm}$. J Biophotonics 30

83. Ferraresi C, Dos Santos RV, Marques G, Zangrande M, Leonaldo R, Hamblin MR, Bagnato VS, Parizotto NA (2015) Light-emitting diode therapy (LEDT) before matches prevents increase in creatine kinase with a light dose response in volleyball players. Lasers Med Sci. doi:10.1007/s10103-015-1728-3

84. Ferraresi C, Beltrame T, Fabrizzi F, Nascimento ES, Karsten M, Francisco CO, Borghi-Silva A, Catai AM, Cardoso DR, Ferreira AG, Hamblin MR, Bagnato VS, and Parizotto NA (2015) Muscular pre-conditioning using light-emitting diode therapy (LEDT) for high-intensity exercise: a randomized double-blind placebo-controlled trial with a single elite runner. Physiother Theory Pract 1-8

85. Gupta A, Keshri GK, Yadav A, Gola S, Chauhan S, Salhan AK, Bala and Singh S (2014) Superpulsed (Ga-As, $904 \mathrm{~nm}$ ) low-level laser therapy (LLLT) attenuates inflammatory response and enhances healing of burn wounds. J Biophotonics

86. Fazilat F, Ghoreishian M, Fekrazad R, Kalhori KA, Khalili SD, Pinheiro AL (2014) Cellular effect of low-level laser therapy on the rate and quality of bone formation in mandibular distraction osteogenesis. Photomed Laser Surg 32:315-321

87. de Jesus VC, Beanes G, Paraguassú GM, Ramalho LM, Pinheiro AL, Ramalho MJ, Rodriguez TT (2015) Influence of laser photobiomodulation (GaAlAs) on salivary flow rate and histomorphometry of the submandibular glands of hypothyroid rats. Lasers Med Sci 30:1275-1280

88. Sperandio FF, Simões A, Corrêa L, Aranha AC, Giudice FS, Hamblin MR, Sousa SC (2014) Low-level laser irradiation promotes the proliferation and maturation of keratinocytes during epithelial wound repair. J Biophotonics. doi:10.1002/jbio. 201400064

89. Larkin-Kaiser KA, Christou E, Tillman M, George S, Borsa PA (2015) Near-infrared light therapy to attenuate strength loss after strenuous resistance exercise. J Athl Train 50:45-50

90. de Carvalho FB, Andrade AS, Rasquin LC, de Castro IV, Cangussu MC, Pinheiro AL, dos Santos JN (2015) Effect of laser $(\lambda 660 \mathrm{~nm})$ and LED $(\lambda 630 \mathrm{~nm})$ photobiomodulation on formocresol-induced oral ulcers: a clinical and histological study on rodents. Lasers Med Sci 30:389-396

91. Tomimura S, Silva BP, Sanches IC, Canal M, Consolim-Colombo F, Conti FF, De Angelis K, Chavantes MC (2014) Hemodynamic effect of laser therapy in spontaneously hypertensive rats. Arq Bras Cardiol 103:161-164
92. Ban Frangez H, Frangez I, Verdenik I, Jansa V, Virant KI (2015) Photobiomodulation with light-emitting diodes improves sperm motility in men with asthenozoospermia. Lasers Med Sci 30:235-240

93. Ramalho KM, de Freitas PM, Correa-Aranha AC, Bello-Silva MS, Lopes RM, Eduardo CP (2014) Lasers in esthetic dentistry: soft tissue photobiomodulation, hard tissue decontamination, and ceramics conditioning. Case Rep Dent 2014:927429

94. Turrioni AP, Basso FG, Alonso JR, de Oliveira CF, Hebling J, Bagnato VS, de Souza Costa CA (2015) Transdentinal cell photobiomodulation using different wavelengths. Oper Dent 40: 102-111

95. Barbosa M, Natoli R, Valter K, Provis J, Maddess T (2014) Integral-geometry characterization of photobiomodulation effects on retinal vessel morphology. Biomed Opt Express 5:2317-2332

96. Havlucu U, Bölükbaşı N, Yeniyol S, Cetinel S, Ozdemir T (2014) Effects of LPT and BioOss ${ }^{\circledR}$ as single and combined treatment in an experimental model of bone defect healing in rats. J Oral Implantol. doi:10.1563/aaid-joi-D-13-00310

97. Tang J, Herda AA, Kern TS (2014) Photobiomodulation in the treatment of patients with non-center-involving diabetic macular oedema. Br J Ophthalmol 98:1013-1015

98. Ekizer A, Uysal T, Güray E, Akkuș D (2015) Effect of LEDmediated-photobiomodulation therapy on orthodontic tooth movement and root resorption in rats. Lasers Med Sci 30:779-785

99. Freire Mdo R, Freitas R, Colombo F, Valença A, Marques AM, Sarmento VA (2014) LED and laser photobiomodulation in the prevention and treatment of oral mucositis: experimental study in hamsters. Clin Oral Investig 18:1005-1013

100. Di Marco F, Di Paolo M, Romeo S, Colecchi L, Fiorani L, Spana S, Stone J, Bisti S (2014) Combining neuroprotectants in a model of retinal degeneration: no additive benefit. PLoS One 9:e100389

101. Montoro LA, Turrioni AP, Basso FG, de Souza Costa CA, Hebling J (2014) Infrared LED irradiation photobiomodulation of oxidative stress in human dental pulp cells. Int Endod J 47: 747-755

102. Pitzschke A, Lovisa B, Seydoux O, Zellweger M, Pfleiderer M, Tardy Y, Wagnières G (2015) Red and NIR light dosimetry in the human deep brain. Phys Med Biol 60:2921-2937

103. Amaroli A, Parker S, Dorigo G, Benedicenti A, Benedicenti S (2015) Paramecium: a promising non-animal bioassay to study the effect of $808 \mathrm{~nm}$ infrared diode laser photobiomodulation. Photomed Laser Surg 33:35-40

104. Naeser MA, Zafonte R, Krengel MH, Martin PI, Frazier J, Hamblin MR, Knight JA, Meehan WP 3rd, Baker EH (2014) Significant improvements in cognitive performance post-transcranial, red/near infrared light-emitting diode treatments in chronic, mild traumatic brain injury: open-protocol study. J Neurotrauma 31:1008-1017

105. do Nascimento RX, Callera F (2006) Low-level laser therapy at different energy densities $\left(0.1-2.0 \mathrm{~J} / \mathrm{cm}^{2}\right)$ and its effects on the capacity of human long-term cryopreserved peripheral blood progenitor cells for the growth of colony-forming units. Photomed Laser Surg 24:601-604

106. Altan BA, Sokucu O, Toker H, Sumer Z (2014) The effect of lowlevel laser therapy on orthodontic tooth movement: metrical and immunological investigation. JSM Dent 2:1040

107. Lanzafame RJ, Stadler I, Kurtz AF, Connelly R, Peter TA, Brondon P, Olson D (2007) Reciprocity of exposure time and irradiance on energy density during photoradiation on wound healing in a murine pressure ulcer model. Lasers Surg Med 39: 534-542

108. Kheshie AR, Alayat ASM, Ali MME (2014) High intensity versus low-level laser therapy in the treatment of patients with knee osteoarthritis: a randomized controlled trial. Lasers Med Sci 29: $1371-1376$ 
109. Karu TI (2010) Multiple roles of cytochrome c oxidase in mammalian cells under action of red and IR-A radiation. IUBMB Life 62:607-610

110. Karu TI, Pyatibrat LV, Afanasyeva NI (2005) Cellular affects of low power laser therapy can be mediated by nitric oxide. Laser Surg Med 36:307-314

111. Karu TI (2008) Mitochondrial signaling in mammalian cells activated by red and near-IR radiation. Photochem Photobiol 84: 1091-1099

112. Enwemeka CS (2009) Intricacies of dose in laser phototherapy for tissue repair and pain relief. Photomed Laser Surg 27:387-393

113. Vayshenker I, Li X, Livigni DJ, Scott TR and Cromer CL (2000) NIST measurement services: optical fiber power meter calibrations at NIST. NIST Spec Publ 250-54

114. Price RBT, Rueggeberg FA, Labrie D and Felix CM. Irradiance uniformity and distribution from dental light curing units. J Esthet Restor Dent, 2010; 22: 86:103

115. Pinheiro ALB, Oliveira MG, Martins PPM, Ramalho LMP, de Oliveira MAM, Novaes Junior A, Nicolau RA (2001) Biomodulatory effects of LLLT on bone regeneration. Laser Ther 13:73-79

116. Bunsen R, Roscoe HE. Photochemische Untersuchungen. Pggendorff's Annalen, 1855; 96: 373-394, 1857; 100: 43-88 and 781-516, 1857; 101: 235-263, 1859; 108: 193-2073

117. Nussbaum EL, Lilge L, Mazzulli T (2003) Effects of low level laser therapy (LLLT) of $810 \mathrm{~nm}$ upon in vitro growth of bacteria: relevance of irradiance and radiant exposure. J Clin Laser Med Surg 21:283-290
118. Bunsen RW, Roscoe HE (1862) Photochemical researches - part $\mathrm{V}$. On the measurement of the chemical action of direct and diffuse sunlight. Proc R Soc London 12:7

119. Karu TI, Kolyakov SF (2005) Exact action spectra for cellular responses relevant to phototherapy. Photomed Laser Surg 23: 355-361

120. Palin WM, Hadis MA, Milward MR, Carroll JD and Cooper PR (2015) Beam profile measurements for dental phototherapy: the effect of distance, wavelength and tissue thickness. Proc SPIE9309. Mechanisms for low-light therapy X, 930905. doi: 10.1117/12.2077628

121. Vandewalle KS, Roberts HW, Rueggeberg FA (2008) Power distribution across the face of different light guides and its effect on composite surface microhardness. J Esthet Restor Dent 20:108117

122. LBA-USB Beam Profiler User Guide. Logan, UT: OphirSpiricon; 2006

123. Price RB, Labrie D, Rueggeberg FA, Felix CA (2010) Irradiance differences in the violet $(405 \mathrm{~nm})$ and blue $(460 \mathrm{~nm})$ spectral ranges among dental light-curing units. J Esthet Restor Dent 22: 363-377

124. Dominici M, Le Blanc K, Mueller I, Slaper-Cortenbach I, Marini F, Krause D, Deans R, Keating A, Prockop D, Horwitz E (2006) Minimal criteria for defining multipotent mesenchymal stromal cells. The International Society for Cellular Therapy Position Statement. Cytotherapy 8:315-317 